\title{
Determinants of willingness to pay for health services: a systematic review of contingent valuation studies
}

\author{
Caroline Steigenberger ${ }^{1}\left(\mathbb{C} \cdot\right.$ Magdalena Flatscher-Thoeni $^{1} \cdot$ Uwe Siebert $^{1,2,3,4} \oplus \cdot$ Andrea M. Leiter $^{5}(\mathbb{C}$
}

Received: 28 May 2021 / Accepted: 12 January 2022 / Published online: 15 February 2022

(c) The Author(s), under exclusive licence to Springer-Verlag GmbH Germany, part of Springer Nature 2022

\begin{abstract}
Introduction Stated preference studies are a valuable tool to elicit respondents' willingness to pay (WTP) for goods or services, especially in situations where no market valuation exists. Contingent valuation (CV) is a widely used approach among stated-preference techniques for eliciting WTP if prices do not exist or do not reflect actual costs, for example, when services are covered by insurance. This review aimed to provide an overview of relevant factors determining WTP for health services to support variable selection.

Methods A comprehensive systematic literature search and review of CV studies assessing determinants of WTP for health services was conducted, including 11 electronic databases. Two of the authors made independent decisions on the eligibility of studies. We extracted all determinants used and related $p$ values for the effect sizes (e.g. reported in regression models with WTP for a health service as outcome variable). Determinants were summarised in systematic evidence tables and structured by thematic domains.

Results We identified 2082 publications, of which 202 full texts were checked for eligibility. We included 62 publications on 61 studies in the review. Across all studies, we identified 22 WTP determinants and other factors from 5 thematic domains: sociodemographic characteristics, perceived threat, perceived benefit, perceived barriers, and other information.

Conclusion Our review provides evidence on 22 relevant determinants of WTP for health services, which may be used for variable selection and as guidance for planning CV surveys. Endogeneity should be carefully considered before interpreting these determinants as causal factors and potential intervention targets.
\end{abstract}

Keywords Contingent valuation $\cdot$ Willingness to pay $\cdot$ Public health $\cdot$ Sociodemographic determinants $\cdot$ Economic valuation $\cdot$ Literature review

JEL Classification D61 Allocative Efficiency · Cost-Benefit Analysis; I11 Analysis of Health Care Markets

Caroline Steigenberger

caroline.steigenberger@umit-tirol.at

1 Institute of Public Health, Medical Decision Making and Health Technology Assessment, Department of Public Health, Health Services Research and Health Technology Assessment, UMIT - University for Health Sciences, Medical Informatics and Technology, Hall in Tirol, Austria

2 Division of Health Technology Assessment, ONCOTYROL, Center for Personalized Cancer Medicine, Innsbruck, Austria

3 Institute for Technology Assessment, Department of Radiology, Massachusetts General Hospital, Harvard Medical School, Boston, MA, USA

4 Center for Health Decision Science, Departments of Epidemiology and Health Policy and Management, Harvard T.H. Chan School of Public Health, Boston, MA, USA

5 Department of Economics, Faculty of Economics and Statistics, University of Innsbruck, Innsbruck, Austria

\section{Introduction}

The concept of willingness to pay (WTP) is used to elicit the consumers' valuation of non-market goods [1]. The consumers' demand for non-market goods can be estimated by contingent valuation (CV) [2]. CV is a practical approach to describe individuals' and society's preferences in various areas such as environment, transportation, education, health care, and others [3]. In the context of resource allocation decisions under restricted budgets, $\mathrm{CV}$ studies can provide information on the value of goods and services where either no market exists or the markets' price information does not reflect the actual costs of goods or service provision.

Health services, defined as activities that provide medical treatment [4], have no market price in a publicly financed health system. Hence, in CV studies, the value of health care 
is described indirectly. CV studies in health care are well established, and the number of publications applying $\mathrm{CV}$ is rising [2, 5]. In CV studies, individuals are asked about their hypothetical WTP for specific services or goods that are usually only requested when a need arises for the individual, for example, through illness [6]. Four value elicitation techniques have been used in health care CV studies: bidding games, open-ended questions, payment cards, and discrete choice questions [7].

Despite the increasing use of CV in health economic evaluation, this approach has weaknesses. Critics question the application of cost-benefit analyses based on stated WTP for interventions or services in a medical context. Some of the main points of criticism refer to challenges in ensuring the validity and reliability of the results. Other concerns address the fact that a hypothetical WTP for a non-market good is prone to errors and systematic biases [8].

The established operationalisation options for the medical benefit usually refer to user- or patient-relevant outcomes such as utilities, quality-adjusted life years (QALYs), prolongation of life, or reduction of morbidity and disability. Since resources in a health care system are scarce, and the system cannot afford maximum treatment for all patients, trade-offs must be made. An efficient allocation of resources requires valid information on how potential beneficiaries and payers value health services. In publicly financed health care systems, the general population pays for the health services of insured individuals via taxes or insurance contributions. The public is, therefore, legitimate to be surveyed in WTP studies [9]. Previous research has shown that the general population, as a heterogeneous group with little specific knowledge of and experience with health services, can determine actual WTP more accurately and consistently than patients or policy-making bodies [10].

Comprehensive knowledge about factors determining the WTP is crucial when planning the study design, data collection, and analysis of a CV study, either as mere statistical predictors or as causal factors of WTP, mediators, effect modifiers, or potential confounders in specific research questions on the determinants of WTP. Some aspects related to $\mathrm{CV}$ in health care have already been investigated and published. Therefore, the research topics of four recently published systematic reviews with meta-analysis were outside the scope of this systematic review. The first review, metaregression analysis of CV studies evaluating the WTP for health care interventions, is from the perspective of chronically ill patients, focussing on the impact of social and cultural aspects at the country level [11]. The second one evaluated health services focussing on the discrepancy between WTP and the willingness to accept [12]. The third and fourth systematic reviews with meta-regression $[13,14]$ aimed at predicting the value that a population assigns to one qualityadjusted life-year (QALY) to inform allocation decisions in health policy when trade-offs are necessary. However, to our best knowledge, there is no systematic review of CV studies that evaluates the range of determinants used to analyse WTP based on the valuation of persons that are not (yet) directly affected. Such information is needed to measure relevant variables and select relevant explanatory variables for regression models to analyse factors determining WTP, particularly if adjustments for covariates are planned. Considering relationships between potential determinants and the outcome(s) is the basis of any good (causal) research question.

Common approaches for variable selection are $p$ valuebased selection (forward, backward, or stepwise selection), as common in medicine and public health, or theory-based selection, as common in economics. Economic (theory) models are helpful to derive which factors influence the value of or demand for services and goods. For example, the Health Belief Model, by Rosenstock [15], describes the relevance of perceived susceptibility, perceived severity, perceived benefits, or perceived barriers on the perceived value of a health service. However, the relationships assumed in economic theory are often challenging to implement empirically because the required data are not available or cannot be recorded precisely. Thus, the question arises, which variables can be used best to represent or approximate the relationships assumed in theory.

We conducted this systematic exploratory review of CV studies in health care from an ex-ante perspective to summarise the currently available evidence on determinants used to analyse WTP for health services. This systematic review merges the approach of theory-based variable selection, as typical in economics, in causal inference, or epidemiology, and $p$ value-based variable selection, as common in finding predictors in clinical prognosis or public health. Combining both approaches helps to improve the regression models by conducting better variable selection and raises awareness for the many facets influencing the perceived value of a health service. We provide an overview of potentially neglected explanatory factors and justify including explanatory variables that lack statistical significance in univariate analysis but are likely to impact WTP. Our intention is not to systematically (and quantitatively) summarise the unbiased effect estimates of WTP determinants. We rather focus on guiding those who plan the analysis of future WTP studies in health care by providing an overview of determinants used in previous studies so that the relevant variables can be considered in the planning of the survey and an explicit decision can be made on including or excluding them in the data collection. Our aim was, therefore, to show which determinants have been used in multivariate regression models with the outcome WTP and which of them actually showed a statistical significance as an indication for potential relevance. 


\section{Methods $^{1}$}

\section{Inclusion and exclusion criteria}

We included publications that reported determinants influencing WTP for health services. The studies had to report the independent variables, which are the basis for our determinants, for the regression model with WTP as the dependent variables. We assessed electronically available full papers published in English or German between January 1999 and October 2021. Our search period starts in 1999 because there is already a comprehensive and transparently reported systematic review until 1998 [5]. For a publication to be included in our review, the study design had to apply the CV method. However, neither the type of the CV method, for example, bidding game, open-ended questions, payment card or discrete choice questions, nor the format of WTP or the type of the regression analysis model, including survival analysis, were restricted. Assessed interventions could be real or hypothetical (e.g. a hypothetical vaccination or treatment). Exclusion criteria included the use of utilities or QALYs as the dependent variable. We also excluded CV studies that asked participants to evaluate the WTP from another person's perspective.

The health services assessed had to be related to human health and medicine. They may concern the area of primary prevention, early detection, diagnostic testing, acute and emergency care and the care of chronically ill persons-in both inpatient and outpatient settings. We did not consider behavioural prevention programmes, assuming that the benefit of the service is challenging for unaffected persons to operationalise and capture the benefit of the intervention. We also excluded studies with veterinary or environmental topics, including disease transmission by animals, for example, via dogs, flies, or mosquitos, dental medicine, and genetic testing for the sole purpose of knowledge.

We applied an ex-ante perspective instead of an ex-post perspective. Numerous studies show that the need of oneself or dependants and the perceived risk impact the WTP [16-19]. Hence, we excluded all studies with pre-selected study populations that already had or currently have the disease of interest that should be cured, treated, or identified. Only restrictions of the study population to a sociodemographic group, such as mothers, men, or elderly persons that can still be considered representative of (parts of) the population, were allowed. Since the results shall be transferable

\footnotetext{
${ }^{1}$ A protocol for this systematic review has been submitted to the Research Committee for Scientific Ethical Questions (RCSEQ) at UMIT - University for Health Sciences, Medical Informatics and Technology. The approval is not available publicly but we can send it if requested.
}

to populations with compulsory health insurance for at least necessary hospital care, studies on supplementary and long-term care insurances were included. In contrast, studies on a general WTP for compulsory health insurance were excluded.

\section{Search strategy}

Our primary sources were databases from various disciplines, supplemented by an unsystematic internet search. The database search included ten electronic databases from economics, health and medicine, psychology, and sociology. The databases were EconLit, ERIC, SocINDEX, PsycINFO, PsycARTICLES, MEDLINE, and PubMed Central (PMC) via PubMed, EMBASE, BIOSIS Previews, and MEDLINE(R) Ahead of Print via $O V I D$. In addition, the interdisciplinary database Web of Science was searched. The search period was from 1 January 1999 to October 2021.

The following search terms were used for the search: "contingent valuation" OR "willingness to pay" combined with a range of search terms describing types of regression analyses, "determinant*", or "predictor". Only for the interdisciplinary database Web of Science, the search term "medical" (all fields) was added to filter the results for our research question. The exact search strings are reported in Appendix A. We also browsed the reference lists for the included full texts to ensure we did not overlook research similar to our review or relevant publications for our analysis.

\section{Selection procedure}

All references found in the 11 databases were collected in the literature management program EndNote and checked for duplicates. Two authors (C. S. and M. F. T.) reviewed the titles and abstracts independently and checked for relevance. For all references that may contain results relevant to the review, the full texts were obtained and again independently checked for eligibility by these two authors. Any discrepancies were resolved by discussion. We applied the same eligibility criteria for an additional article from another source (expert referral); only the documentation in the flow chart in Fig. 1 is different, as only suitable publications were included.

The methodological quality of the included studies was not assessed. The wide variation in question types and elicitation formats makes classification and appraisal of the literature difficult. There is a lack of an appropriate quality assessment tool for CV studies. The applicability of the guidelines issued by the National Oceanic and Atmospheric Administration (NOAA) panel [20] for environmental economics is unclear for our health care setting, as also stated by Diener et al. [7]. A suitable appraisal of the quality of CV studies would include questions on the research aim, 


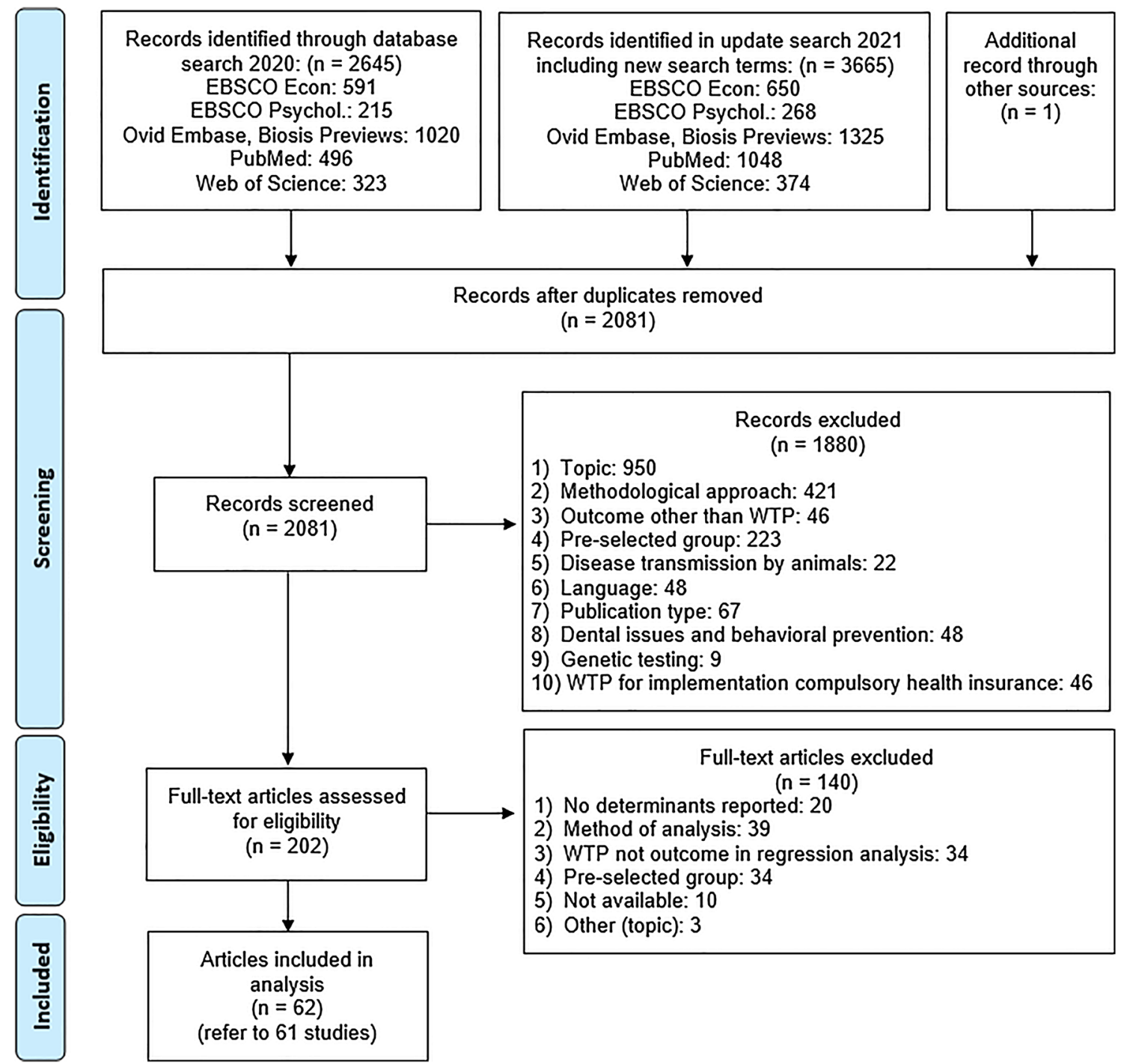

Fig. 1 PRISMA flow chart for the selection of studies

the scope of the research question, which type of measure is used (compensation or equivalent valuation), and with which direction (WTP or willingness to accept) [21]. Since our inclusion and exclusion criteria are specific for the research aim of this systematic review, we eliminated some of the potential biases by focussing on studies from an ex-ante perspective evaluating WTP for health services that imply a gain for the user/respondent (directly or indirectly) and the stated WTP serves as compensation for receiving the option for the health service. The validity of an included study as cost-benefit evaluation would not be relevant for the primary research question of this review: which determinants were used in the full regression models evaluating WTP for health services and which of these had, according to the authors, a statistically significant influence on WTP?

\section{Data extraction and synthesis}

Systematic extraction forms and evidence tables were developed before the literature search, which contained the following parts to summarise the content of the included publications:

1) Study characteristics: name of the first author, year of publication, objective of the study, location of the study, time of recruiting and data collection, study population and study centres, number of participants analysed in the regression model, gender, and age of the participants (Table 1).

2) Methodological information: data collection, attributes of the CV method used, and the type of regression analysis (Table 2). 
3) Determinants used as explanatory variables in the full regression models with information on the frequency of use and the level of statistical significance (Tables 3 and 4) are the primary outcomes of our review.

The determinants result from the text analysis of the included publications. We defined a "determinant" as an individual independent factor in a regression model. Each determinant may comprise a thematic set of synonymous or comparable explanatory variables. In addition to age and gender, we generated new determinants deductively during the extraction process based on the aspects used in the regression models reported in the publications. We summarised the used determinants thematically and yielded superordinate domains. In addition to the domain "sociodemographic factors", we used the concepts from the Health Belief Model [15] as separate domains that allow a clear distinction. The four original concepts of the theoretical model are "perceived threat" (including perceived susceptibility and severity of disease), "perceived barriers", and "perceived benefits". Table 6 describes the domains in more detail.

Each publication was summarised in one table row in the systematic evidence tables, even if multiple regression models were described with WTP as the dependent variable. If multiple regression models were compared in one publication or there was more than one variable or variable characteristic addressing the same determinant (e.g. several dummy variables describing multiple income categories), the most decisive result, respectively, the lowest $p$ value reported, was used, regardless of how many other variables had a higher $p$ value. If a pooled model was reported for the entire study population, the results of the pooled model were chosen. While this simplification tends to yield more statistically significant determinants relative to the determinants used, this adjustment was necessary for the summary of results. Since the aim of the review is exploratory, this simplification is not expected to result in a loss of information.

To compare the frequency of use of determinants in regression models, we generated three different scoring options per determinant:

1) Statistically significance/trend: the explanatory variable showed an association with WTP that was statistically significant $(p<0.05)$ or indicated a trend (i.e. $p \leq 0.1)$

2) No statistically significance/trend: no explanatory variable showed a statistically significant association (or trend) with WTP (n.s.)

3) The determinant was not used in the full regression model (n.u.)
Data were extracted from the publications by one author (C. S.) and verified by a second author (M. F. T.). Questions arising during the extraction process were solved by discussion. We report use and statistical significance per determinant and study in an extraction table (Table 3) and summarise determinants and frequency of use in a systematic evidence table (Table 5). The detailed results of the evaluation according to the characteristics "statistically significant impact on WTP", "no statistically significant impact", and "not used" are reported in Table 3. For each determinant, we calculated the relative frequency for the use of this determinant about all publications (see column 2 in Table 5) and the proportion of being statistically significant compared to all studies in the review (see column 3 in Table 5). We did not calculate average values for "additional information".

Finally, we derived thematic domains based on the determinants identified. The determinant labels and descriptions of the domains were critically discussed between all the authors until consensus was reached.

\section{Results}

\section{Study selection}

The database search yielded 6310 hits, and one additional publication was included due to an expert recommendation. After removing duplicates, 2081 titles and abstracts were checked for eligibility and inclusion in the review. After this step, 202 publications were checked as full texts for eligibility. Sixty-two publications met the inclusion criteria and were included in the review. The selection process documentation with reasons for exclusion is shown in the PRISMA flow chart in Fig. 1.

Most records were excluded because the topic of the publication did not fit the research question or had no relation to health or medicine (e.g. addressing environmental issues, nutrition, societal or social issues, or methodological aspects). Further records were removed as they did not apply the CV method (e.g. cost-effectiveness studies or discrete choice experiments without explicit results for determinants or health services). A list with the references of all excluded full texts can be found in Online Resource 1 . The 62 publications included refer to 61 different $\mathrm{CV}$ studies.

\section{Description of studies}

As described in Table 1, the studies included in this review were conducted in 45 countries in Asia, Africa, Europe, North and South America. Across the 62 studies, data of a total of 61,983 participants were included in the regression analyses. In 31 publications referring to 30 studies, data were collected via interviewer-administered CV 


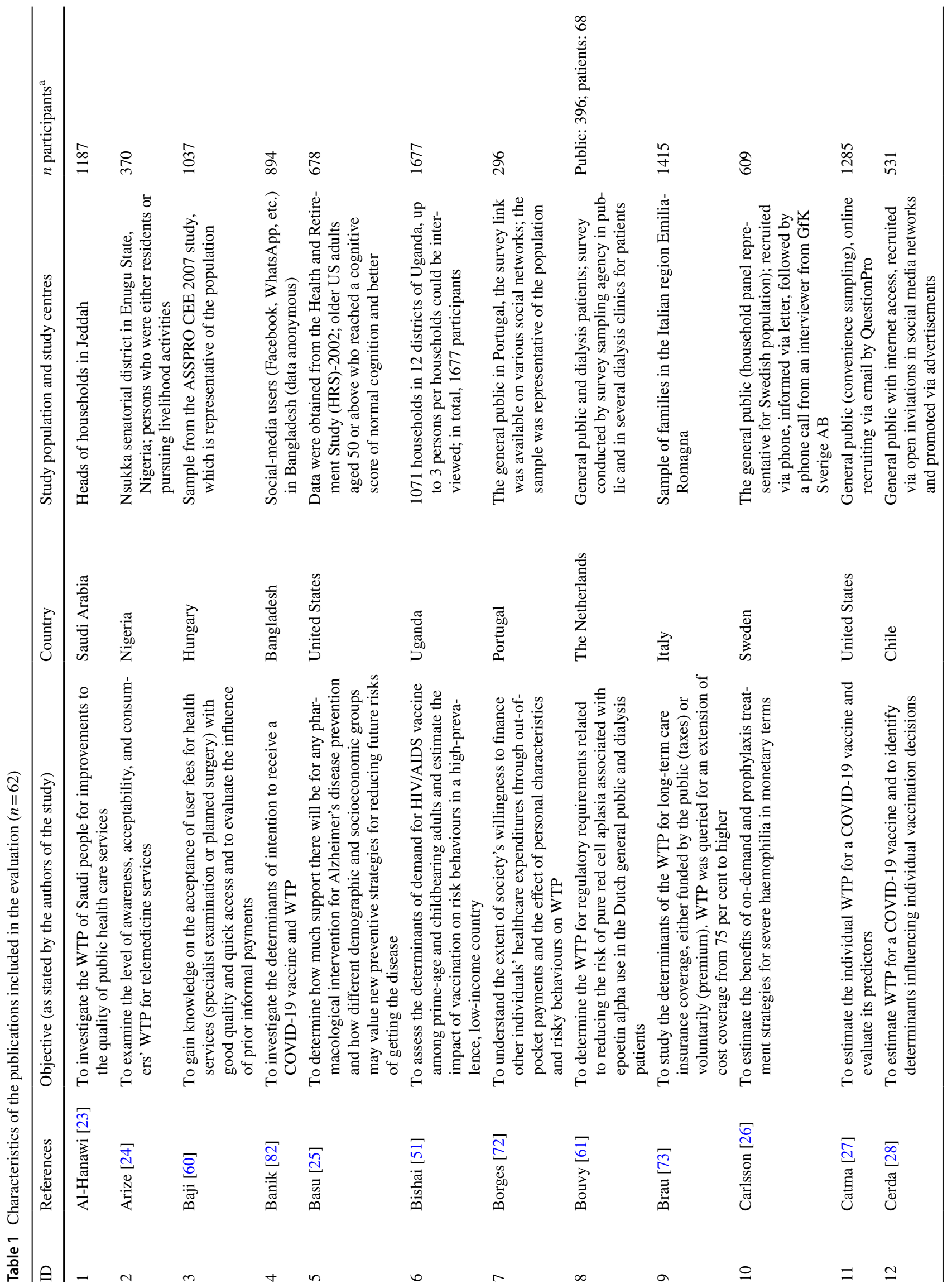




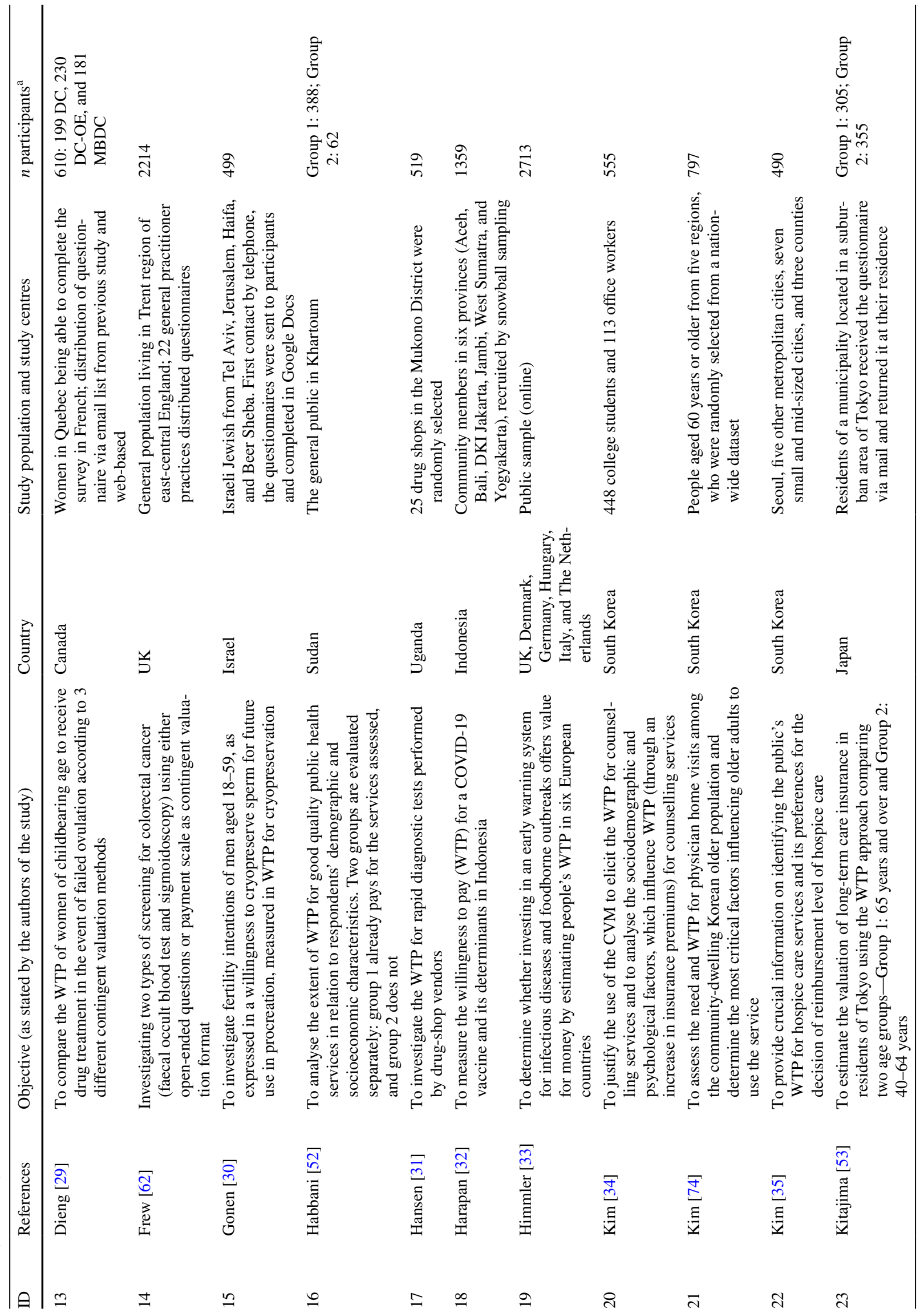




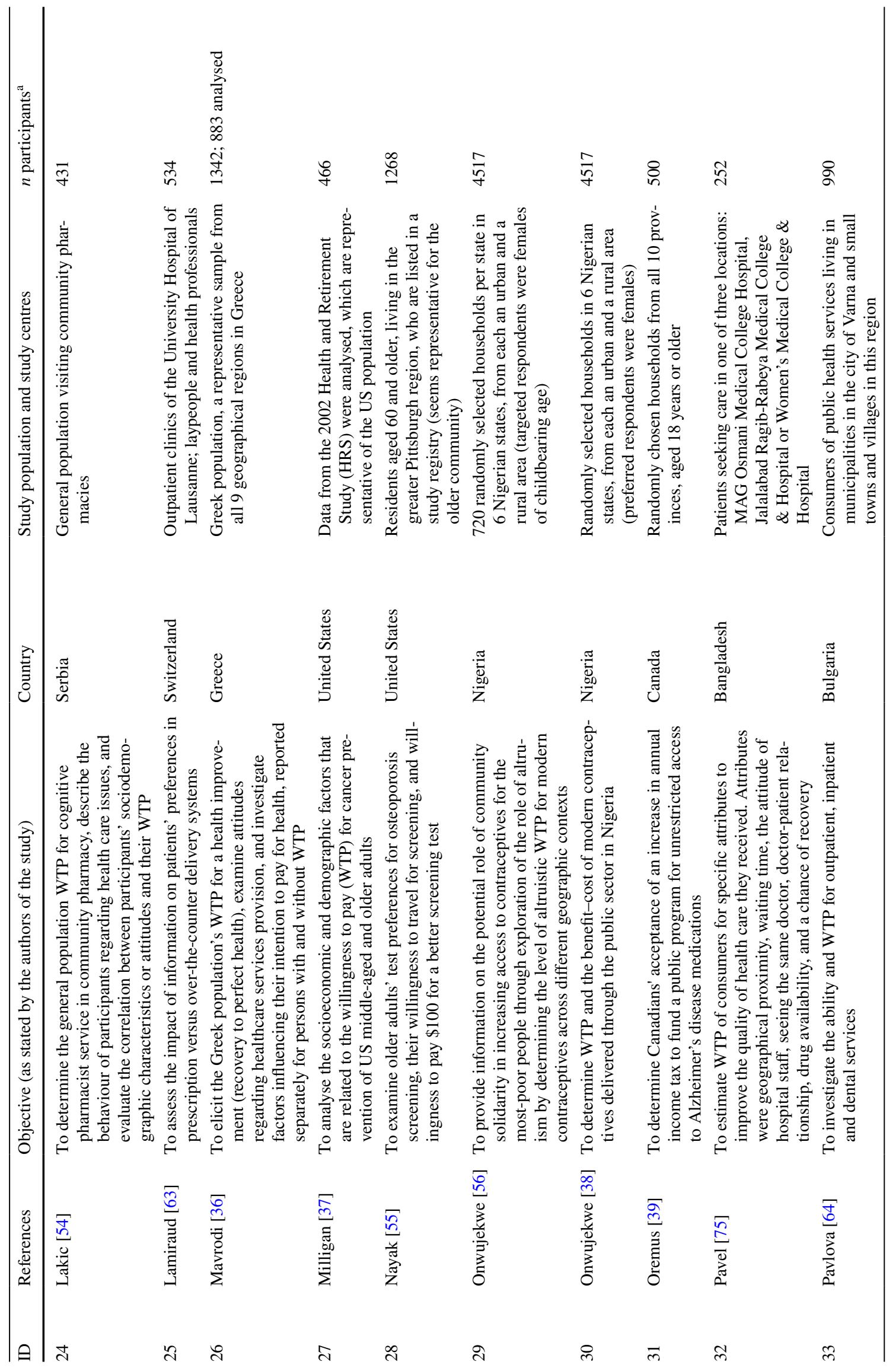




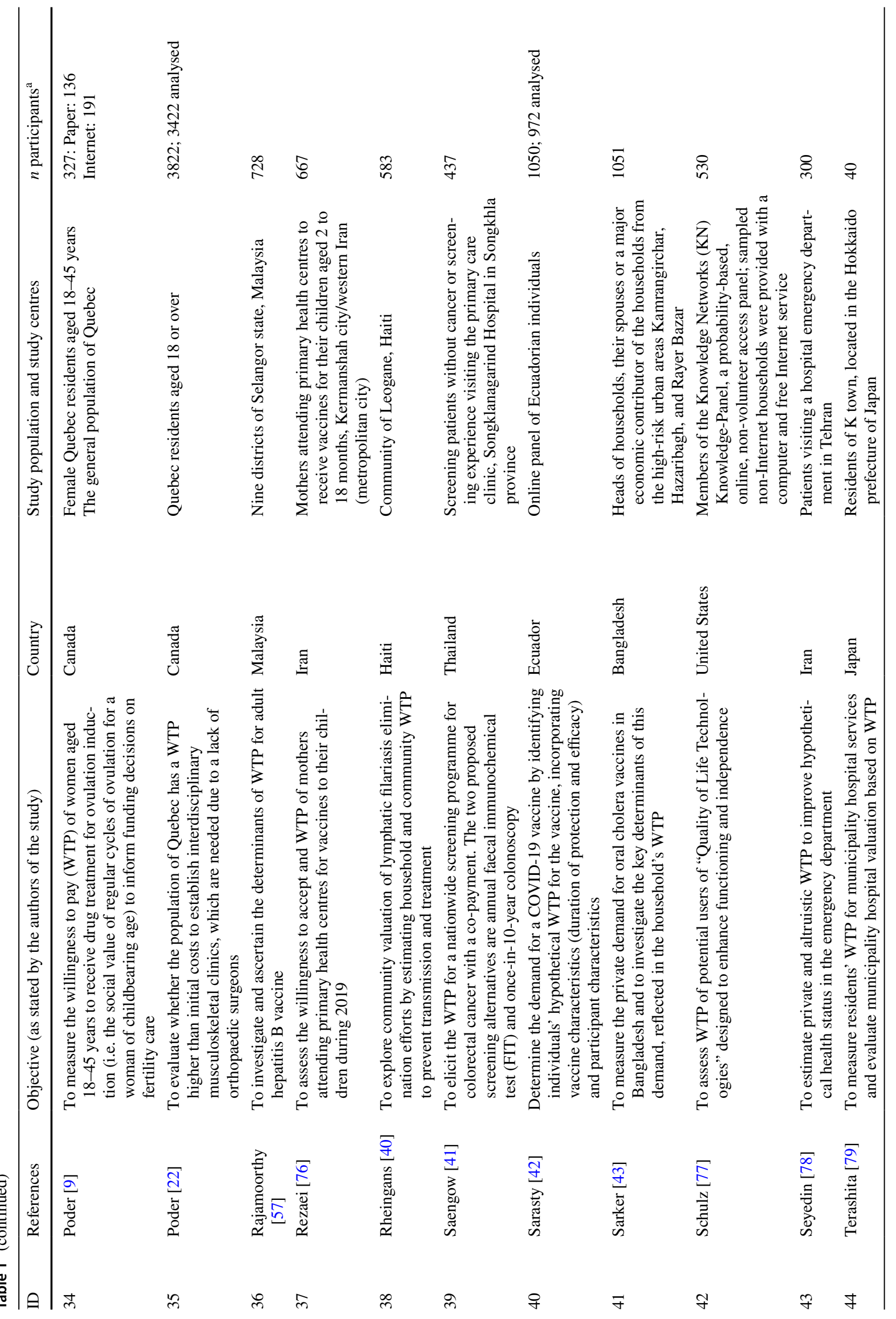




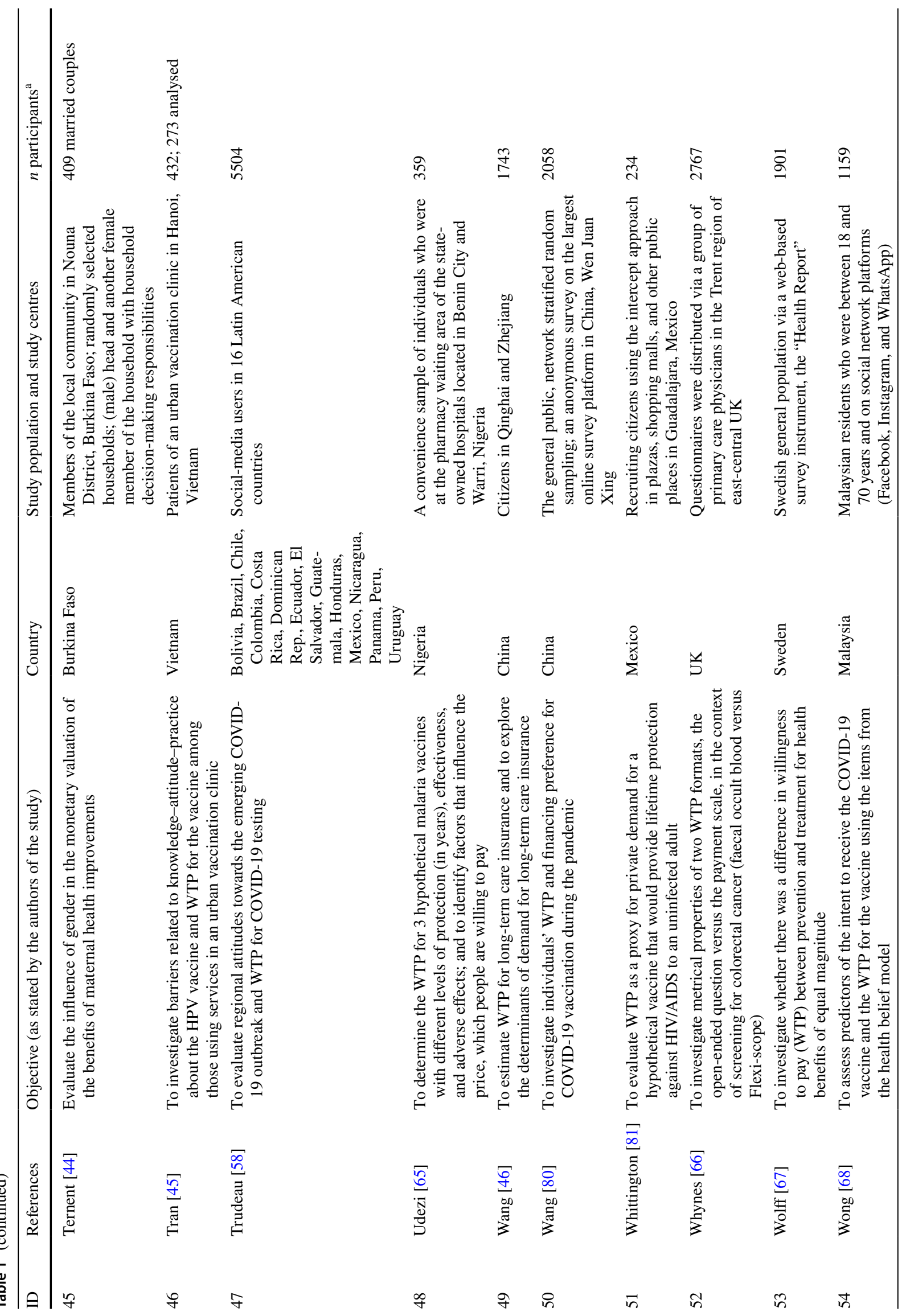




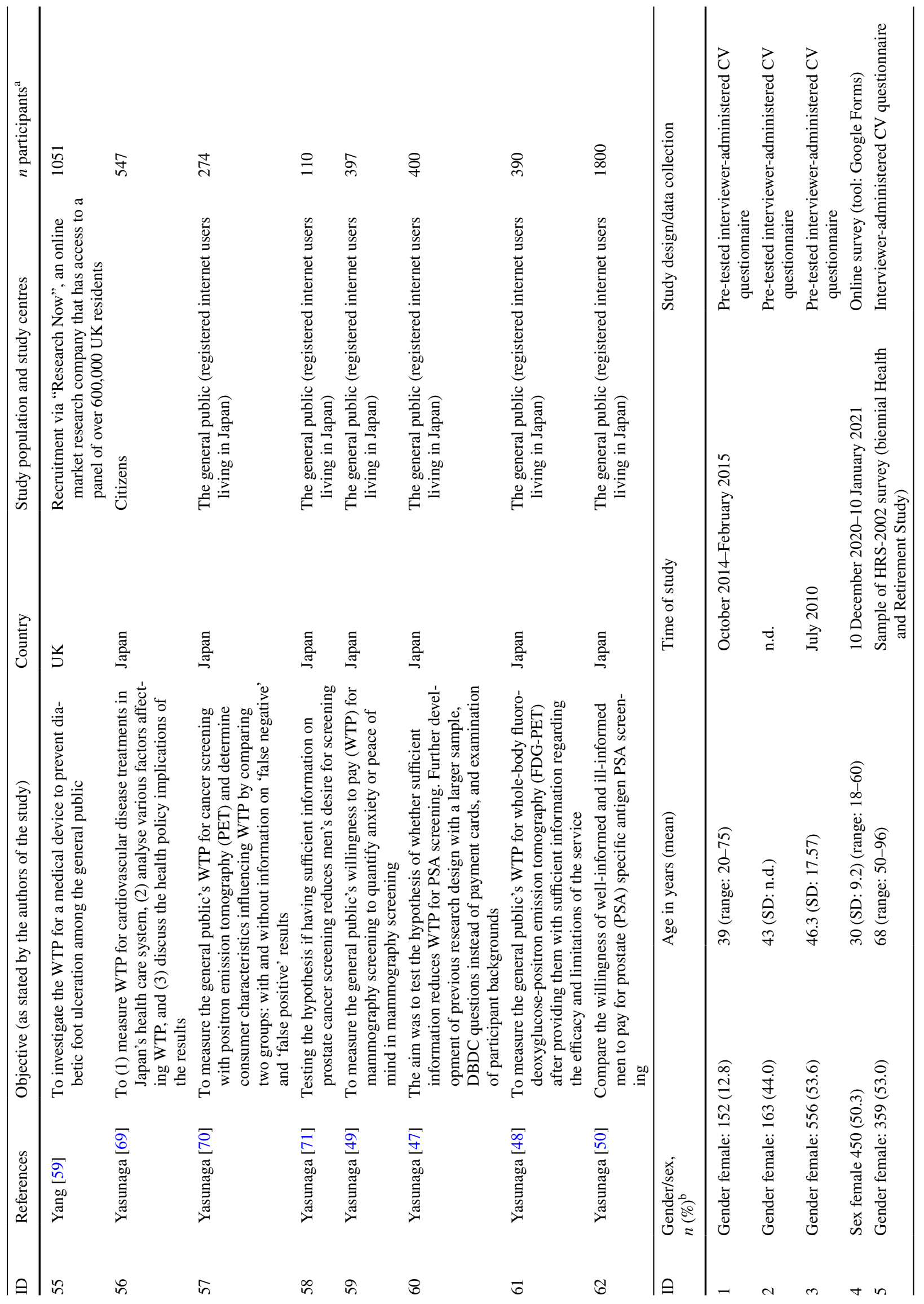




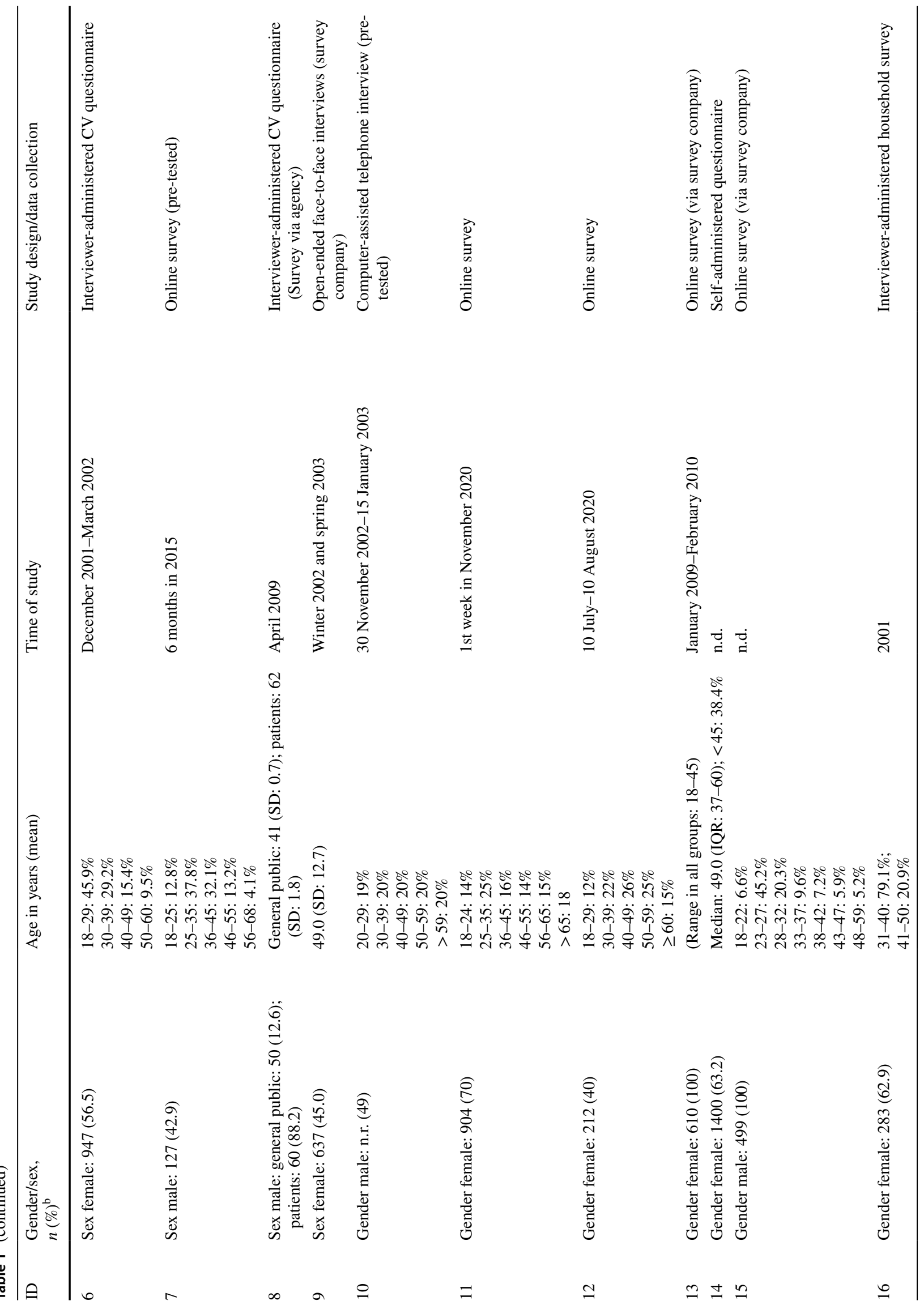




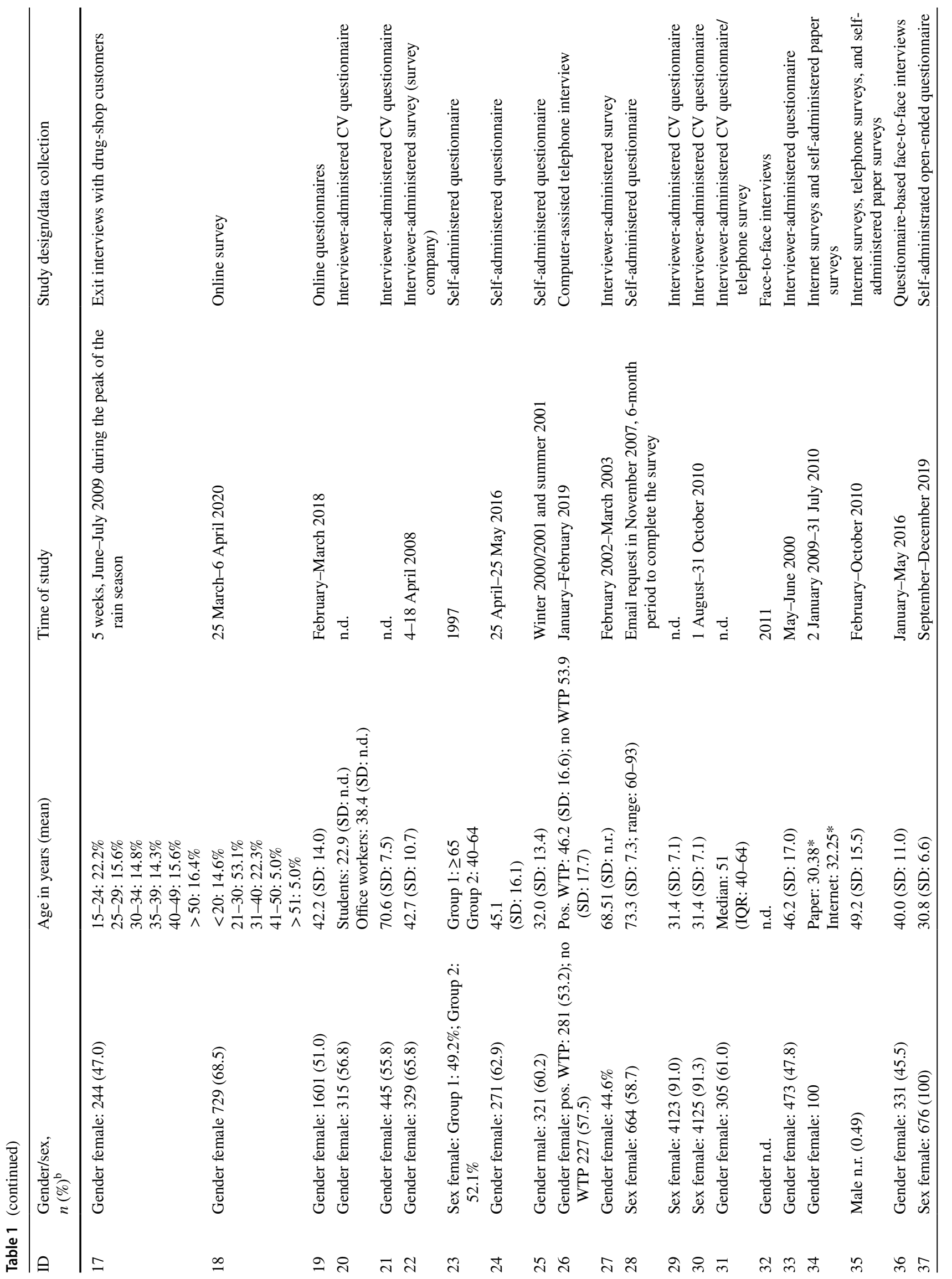




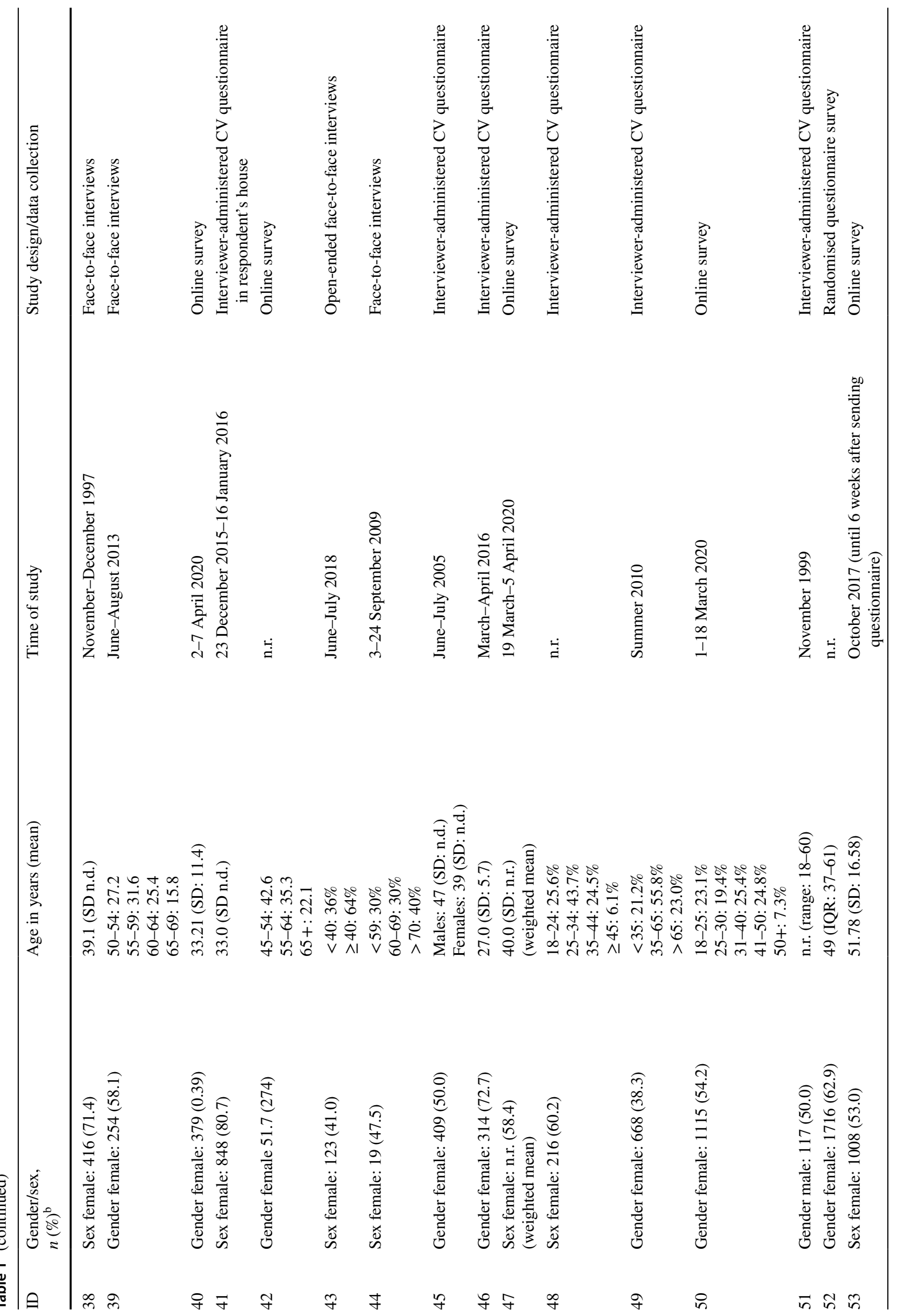




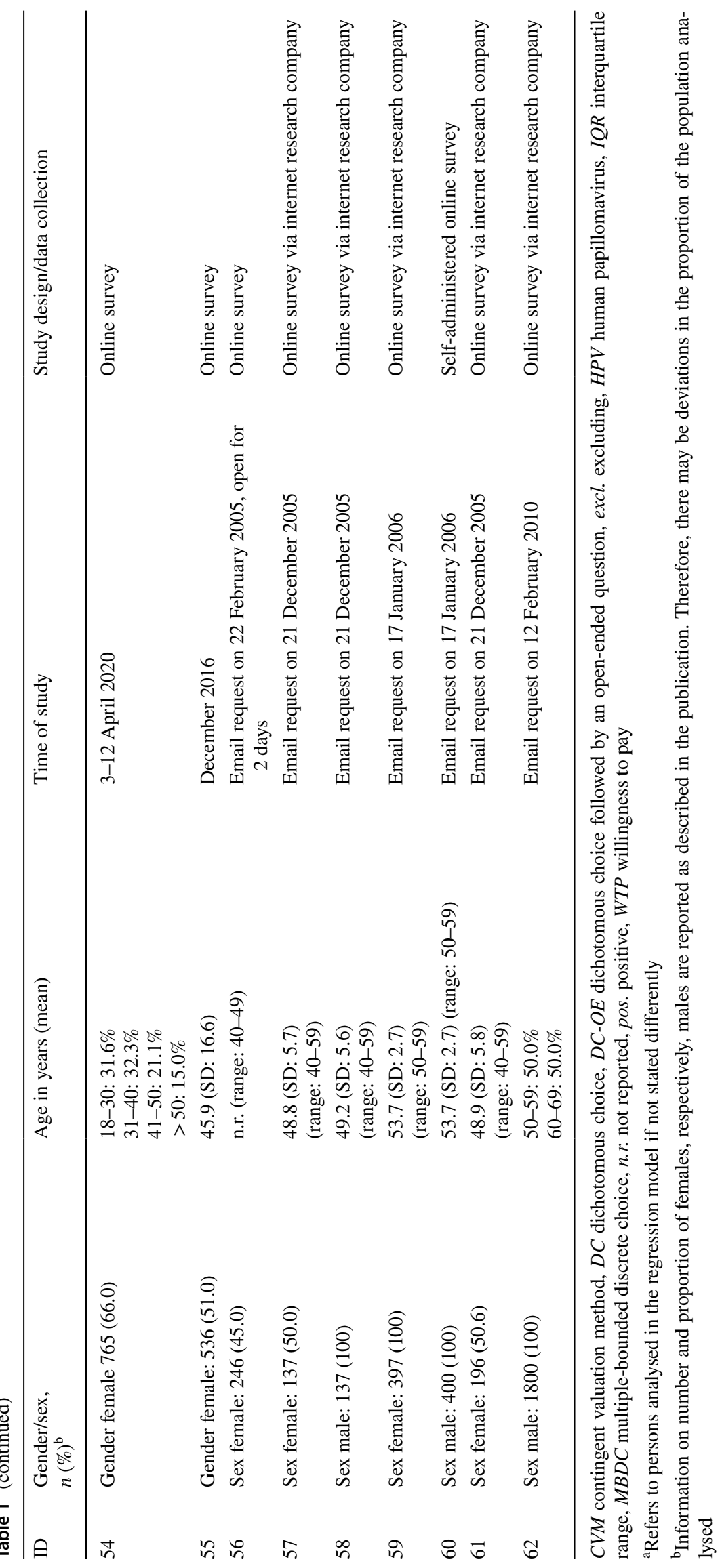




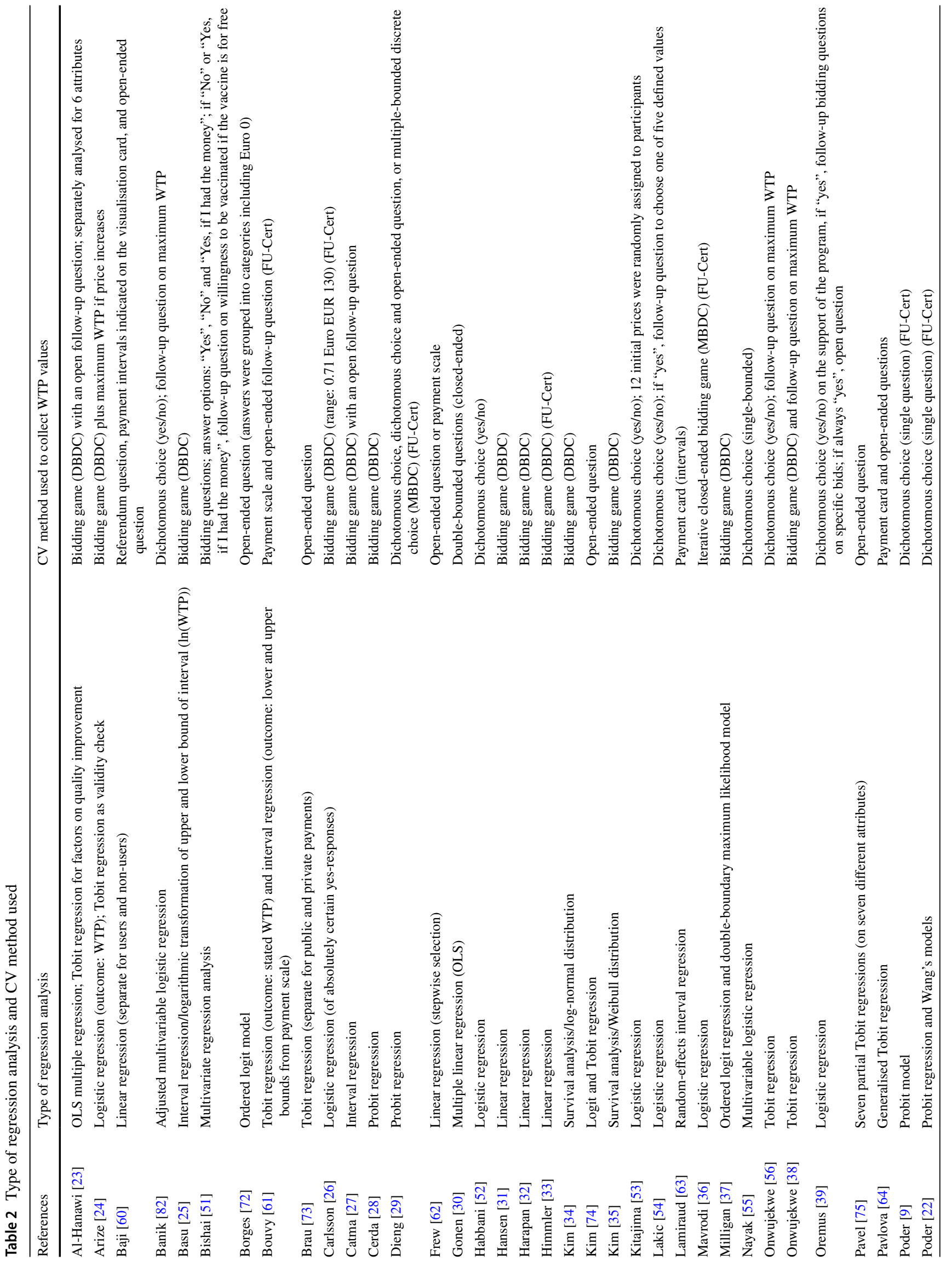




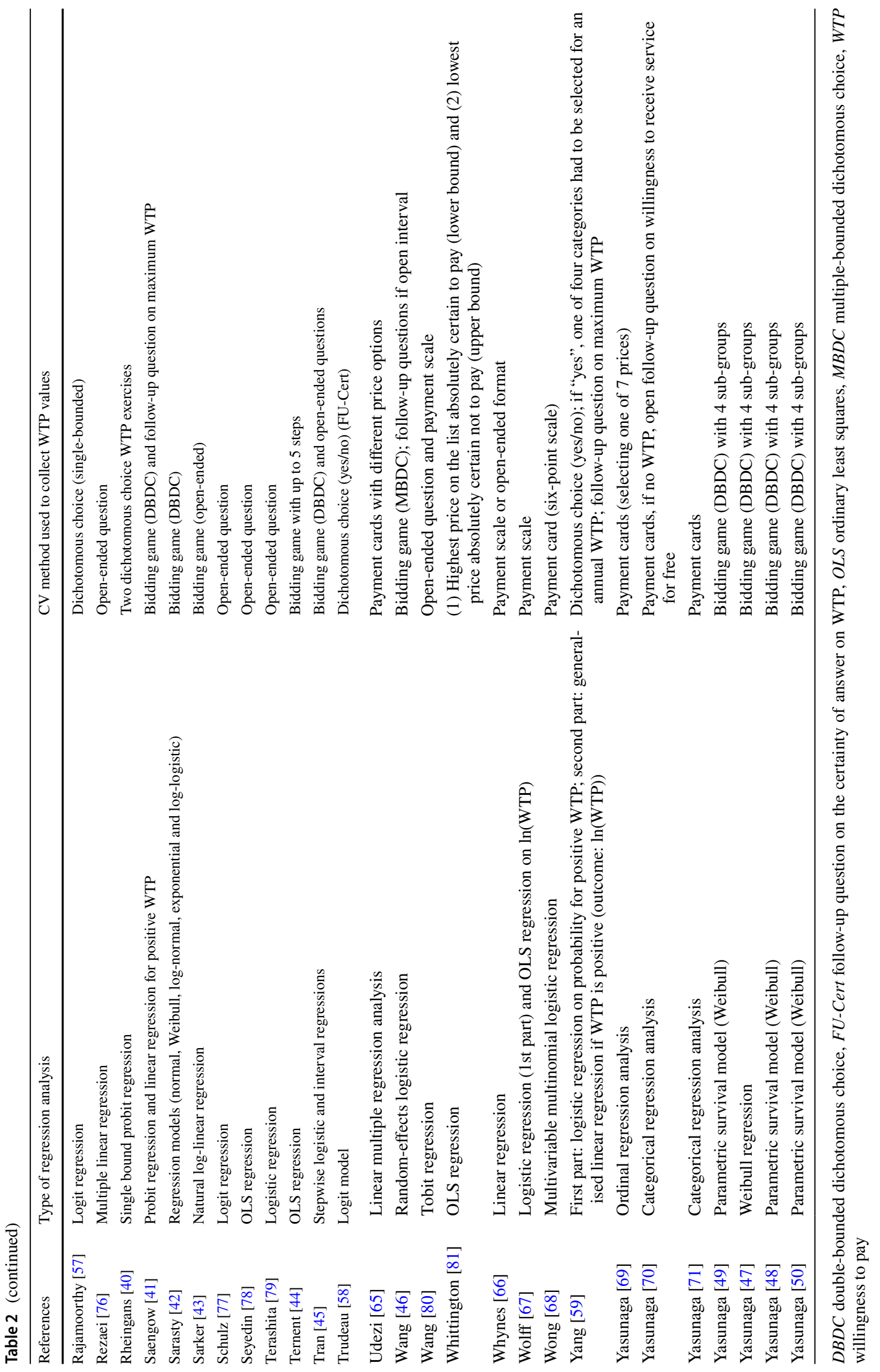


questionnaires, either in person or via telephone. In 33 studies, participants filled the questionnaires themselves, either online or anonymously in printed form. Two studies used both administration modes [9, 22]. The proportion of women and men differed across studies. Differences were usually related to the study setting, the accessibility of respondents, or the research question. Twenty-two studies were published from 1999 to 2010 and 40 since 2011.

The CV study design, the types of the regression models, and the format of the WTP variable differ between studies, as described in detail in Table 2. Twenty-eight studies [23-50] applied a bidding game with double-bonded dichotomouschoice questions or more than two bidding questions, 13 studies [9, 22, 29, 51-59] used single dichotomous choice, 13 studies [60-71] applied payment cards, and 13 studies $[62,64,66,72-81]$ applied open questions as the primary survey method for WTP. Five studies [29, 62, 64, 66, 80] applied more than one WTP format. Of the studies using a bidding game, single dichotomous choice, or payment cards, 13 [23, 24, 27, 29, 38, 39, 41, 46, 54, 56, 59, 60, 82] added an open-ended follow-up question on WTP and eight [9, $22,26,29,33,36,58,61]$ used a follow-up question on the certainty of their answer on WTP. According to the research question and variable definition, regression methods applied included multiple linear, log-linear, logistic, ordinal, Tobit, Probit, and interval regression analyses as well as (parametric) survival analyses (see Table 2).

\section{Identified determinants and domains}

A total of 22 determinants were found, plus the category "other variables", as described in Table 4. Each table cell represents one of the 1364 evaluations-separately for 62 publications and 22 determinants each (additional variables excluded).

As shown in Table 5, over half of the studies used the following determinants in their multivariate regression models: "age", "gender/sex", "education", "income/wealth", "perceived own susceptibility", and "affectedness/perceived severity of disease". The category "other variables" comprises the determinant "methods and setting" of the study and fourteen additional variables (reported in Table 6) on heterogeneous factors that are relevant to specific research topics, for example, by describing differences in the study population or motivation for the health service. For example, we did not generate a new determinant for socioeconomic variables that were very specific to the context of a single country (e.g. "status of the respondent in the household" $[38,56])$ or only used once and without a statistically significant influence on WTP (e.g. the number of persons with income in a household [79]). These variables were diverse and, therefore, summarised as "additional variables".
The number of variables used differed substantially between studies. The 62 publications, each including one or more regression models with WTP as the dependent variable, used on average 8.3 determinants (median 8; range 3-12) per study, of which on average five determinants (median 5; range 0-12) per study were statistically significant (see right column of Table 3 ). When comparing the groups, $61.1 \%$ of the determinants used showed a statistical significance or trend. Without the most used sociodemographic determinants "age", "gender/sex", "education", and "income/wealth", the number of determinants used is reduced to 5.1 per publication (median 5; range 1-10), of which $3.0(57.7 \%)$ show statistical significance or trend. This narrow range of explanatory variables indicates a potentially too restrictive variable selection.

Based on the determinants used, five domains were derived: "sociodemographic characteristics", "perceived threat", "perceived benefits", "perceived barriers", and a group of variables that covered methodological aspects and study-specific aspects depending on the research question, called "other information". Table 6 shows the domains and the corresponding determinants and operationalisation, with a brief description of the domain. The labelling of three of the domains, "perceived threat", "perceived benefit", and "perceived barriers", is identical to the categories from the Health Belief Model (Rosenstock 1966) [15] because the established categories are separable and fit the determinants we found. It was not our original intention to map the determinants to the categories from the Health Belief Model; however, these categories were a perfect fit for our determinants. Some of the studies [27, 28, 32, 57, 68, 80, 82] also used the categories from the Health Belief Model for their data collection and thus reported corresponding variables.

By far the largest domain was "sociodemographic characteristics" ( $n=287)$, followed by "perceived threat" $(n=111)$, including the susceptibility for and severity of condition or risk, "perceived benefit" $(n=56)$, including pre-knowledge and non-health benefits, and "perceived barriers" $(n=58)$ describing costs and barriers for access. Besides the most frequently measured socioeconomic variables in this domain [age $(n=50)$, gender $(n=41)$, education $(n=45)$, and income $(n=57)$ ], over two-thirds of the studies used determinants describing the situation of the respondent: "perceived own susceptibility" $(n=32)$, "affectedness/perceived severity" ( $n=33)$, and "personal mindset (affected relatives or attitude of living healthy)" ( $n=30)$. These aspects help to understand the respondent's situation, subjective influence factors on WTP (e.g. perceived stigma [34]), and potentially conflicting interests for the money spent. For example, in one study, the mindset that the state should pay essential long-term care services to all versus only to the poor had a statistically significant association with WTP $(p<0.01)$. 


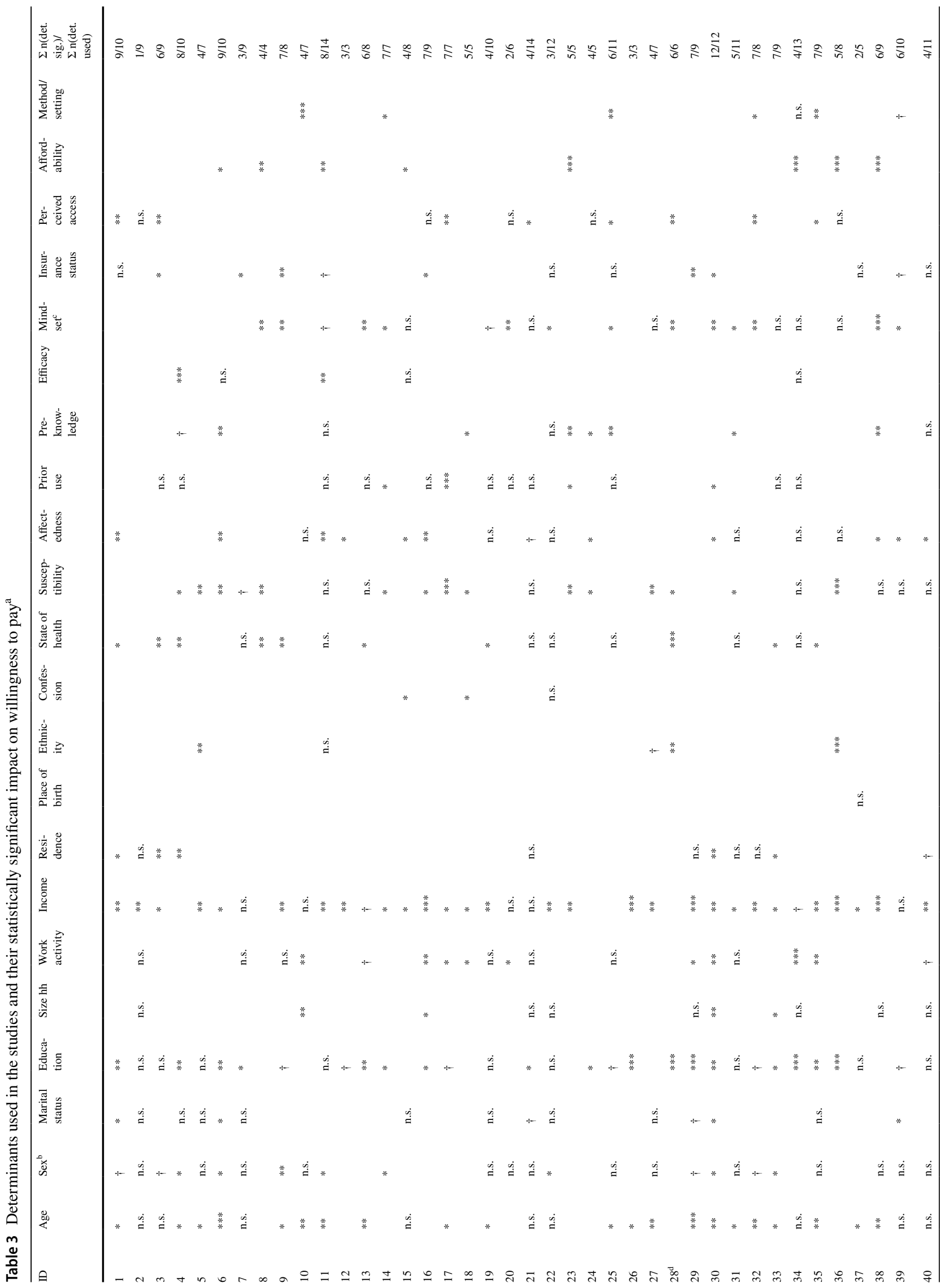




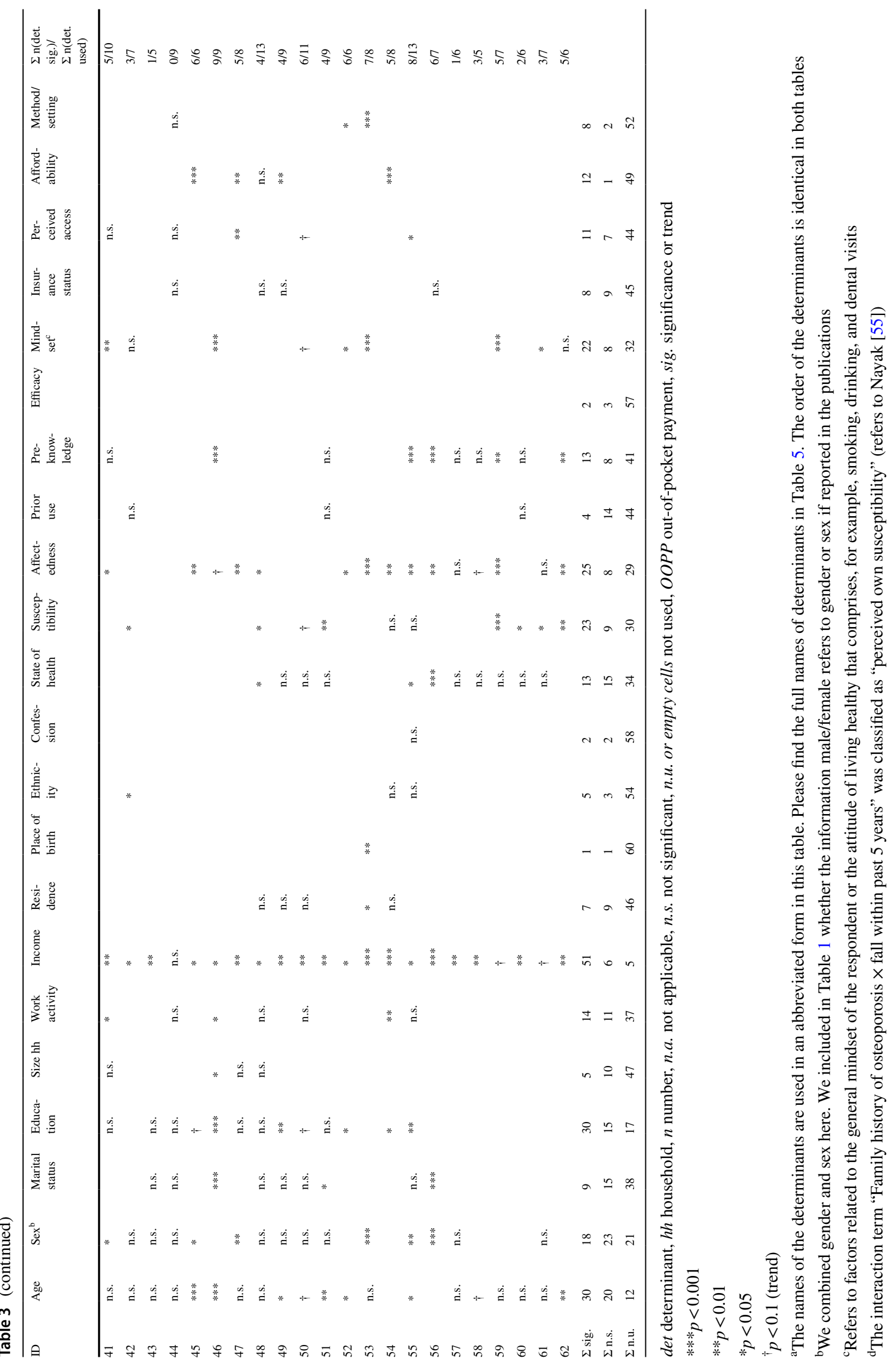


Table 4 Other variables (not assigned to other determinant categories)

\begin{tabular}{lll}
\hline References & Variable & Significance level \\
\hline Baji [60] & Respondent is on sick pension & n.s \\
Catma [27] & Perceived effectiveness of policy measures & $*$ \\
Lakic [54] & Pharmacists are seen as a source of information about medicines & $*$ \\
Onwujekwe [38, 56] & Status in household & n.s./** \\
Pavel [75] & Nature of the setting, private versus governmental hospital & $*$ \\
Pavel [75] & Reason of medical visit acute & n.s. \\
Poder [9] & Having a child & n.s. \\
Rezaei [76] & Sex of the child & n.s. \\
Schulz [77] & Concern about privacy & $*$ \\
Terashita [79] & Number of persons with income & n.s. \\
Wang [80] & Employee size in the workplace & $* *$ \\
Whynes [66] & protest expressed at the idea of payment & $*$ \\
Wong [68] & I am concerned if the new COVID-19 vaccine is halal & $* * *$ \\
Wong [68] & I will only take the COVID-19 vaccine if the vaccine is taken by & n.s. \\
& many in the public & \\
\hline
\end{tabular}

n.s. Not significant

${ }^{*} p<0.05$

$* * p<0.01$

$* * * p<0.001$

${ }^{\dagger} p<0.1$ (trend)
A comparison between the six geographical regions according to the World Bank [83], Africa, East Asia and Pacific, Europe and Central Asia, Latin America and the Caribbean, Middle East and North Africa, and South Asia, indicates very little influence of the World Bank region on the type of sociodemographic variables seen as relevant to describe the study sample. There were no major differences in the determinants used, as presented in Table 3. Variables on cultural differences might be more present in studies with high heterogeneity of the study population, which is more likely in countries with international citizenship and different main confessions. For example, "ethnicity" was primarily assessed in societies with a heterogeneous population as the United States, UK, and Malaysia [25, 27, 37, 55, 57, 59, 68]. The determinant "number of persons with income" was only assessed in a study from Japan [79]. "Confession/level of religiosity" only had a statistically significant influence in Israel and Indonesia. Only one study [33] comparing six European countries addressed cultural differences between countries in more detail and identified variations in income and risk aversion as the main differences between countries.

\section{Discussion}

This systematic review provides an overview of determinants used in multivariate regression models to analyse WTP for health services in the specific context of ex-ante evaluations of a health service by the general public using $\mathrm{CV}$. We compiled this review of CV studies published since 1999 to show potentials for improvement in the current practice of analysing CV studies. We extracted the explanatory variables used in multivariate regression models, summarised them in 22 determinants, which could be compared across studies, and derived five thematic domains: "sociodemographic characteristics", "perceived threat", "perceived benefit", "perceived barriers", and "other information".

In this review, all determinants showed a statistically significant association (or trend) with WTP in at least one study. Such statistical association does not necessarily imply an independent causal relationship between the determinant and WTP. While the integration of sociodemographic variables was relatively common, other domains were mainly neglected. This fact is important because the variables from the lesser used domains predominantly show statistically significant impact on WTP if they were used. Consequently, based on the reviewed scientific literature, we suggest considering also rarely used variables as potential determinants for WTP. Examples of potentially relevant determinants that are rarely used are prior knowledge, information, attitude towards the health service, perceived risk, and affectedness. The narrow range of explanatory variables used (median 8 ; range 3-12) with a high proportion of statistically significant determinants ( $61.1 \%$ of determinants used) might be a problem since $p$ value-based and model-based variable selection methods do not always adequately control for confounding [84]. Some explanatory factors or interactions between variables might be overlooked, even if they make the difference. 
Table 5 Summary of determinants used in regression models

\begin{tabular}{|c|c|c|}
\hline Determinant including different characteristics & $\begin{array}{l}\text { Studies using deter- } \\
\text { minant } \\
n(\%)^{\mathrm{a}}\end{array}$ & $\begin{array}{l}\text { Statistical } \\
\text { significance/ } \\
\text { trend } \\
n(\%)^{\mathrm{b}}\end{array}$ \\
\hline Age (in years or as a grouped variable) & $50(80.64)$ & $30(60.0)$ \\
\hline Gender/sex (reference category "male" or "female") & $41(66.12)$ & $18(43.9)$ \\
\hline Marital status & $24(38.70)$ & $9(37.5)$ \\
\hline Education & $45(72.58)$ & $30(66.7)$ \\
\hline Size household/family & $15(24.19)$ & $5(33.3)$ \\
\hline Work activity/job type & $25(40.32)$ & $14(56.0)$ \\
\hline Income/wealth & $57(91.93)$ & $51(89.5)$ \\
\hline Geographic location and residence setting & $16(25.80)$ & $7(43.8)$ \\
\hline Place of birth (country or urban/rural) & $2(3.22)$ & $1(50.0)$ \\
\hline Ethnicity (nationality/race) & $8(12.90)$ & $5(62.5)$ \\
\hline Confession/level of religiosity & $4(6.45)$ & $2(50)$ \\
\hline State of health & $28(45.16)$ & $13(46.4)$ \\
\hline Perceived own susceptibility & $32(51.61)$ & $23(71.9)$ \\
\hline Affectedness/perceived severity of disease & $33(53.22)$ & $25(75.8)$ \\
\hline Prior use/disease history & $18(29.03)$ & $4(22.2)$ \\
\hline Pre-knowledge/information & $21(33.87)$ & $13(61.9)$ \\
\hline Efficacy/effectiveness & $5(8.06)$ & $2(40.0)$ \\
\hline $\begin{array}{l}\text { Personal mindset (affected relatives)/attitude of living healthy } \\
\text { (smoking, drinking, dental visits) }\end{array}$ & $30(48.38)$ & $22(73.3)$ \\
\hline Insurance status (including prior OOPP) & $17(27.41)$ & $8(47.1)$ \\
\hline Perceived access (incl. waiting time and forgoing use) & $18(29.03)$ & $11(61.1)$ \\
\hline Price of treatment and affordability & $13(20.96)$ & $12(92.3)$ \\
\hline Methods and setting & $10(16.12)$ & $8(80.0)$ \\
\hline Marital status & $24(38.70)$ & $9(37.5)$ \\
\hline
\end{tabular}

incl. Including, $N$ number, n.a. not applicable, $O O P P$ out-of-pocket payment

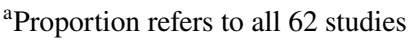

${ }^{\mathrm{b}}$ Refers to the number of regression models using the determinant and describes the proportion of determinants with statistical significance or trend (i.e. level of $p<0.1$ ) among all studies that used this determinant

${ }^{c}$ We combined gender and sex here. If reported in publications, we included in Table 1 whether the information male/female refers to gender or sex

Table 6 Domains/areas of determinants

Domain Determinants/operationalisation of domain

1. Sociodemographic characteristics

2. Perceived threat (= susceptibility for and severity of condition or risk)

3. Perceived benefit (also non-health-related benefits) and pre-knowledge

4. Perceived barriers (= belief about tangible and psychological cost)

5. Other information
Age, gender/sex, marital status, education, size household/family, work activity/job type, income/wealth, geographic location/residence setting, place of birth (country or urban/rural), ethnicity (nationality/ race), confession/level of religiosity

State of health, perceived own susceptibility, affectedness/perceived severity of disease, prior use/disease history

Efficacy/effectiveness, personal mindset (affected relatives)/attitude of living healthy (smoking, drinking, dental visits), pre-knowledge/ information

Insurance status (including prior OOPP), perceived access (incl. waiting time and forgoing use), price of treatment and affordability

Methodological variables and study setting,

Additional variables $(n=14$, reported in Table 4$)$ 
For example, suppose a disease is not perceived as severe. In that case, there is already an explanation as to why a bad state of health or one's own susceptibility does not have a statistically significant impact on WTP even if there is a realistic threat based on scientific evidence. We excluded the domain "other information" from the quantitative comparison of use and statistical significance. Variables in this domain were related to the analysis method, the setting, and the research question (listed in Table 4). These aspects are just as important as other domains but were diverse and difficult to summarise.

Unexpectedly, the main variables describing the scope of the health service, the price of the treatment, and efficacy were rarely used as determinants. In addition, hypothetical bias and scope effect were often addressed as a typical bias of $\mathrm{CV}$ studies in the introduction or discussion sections of the studies. Still, only a few studies took sufficient action to reduce the bias; for example, eight studies [9, 22, 26, $29,33,36,58,61,81]$ asked the respondent in a follow-up question for their certainty regarding stated WTP. Previous literature has shown that methodological issues as different payment vehicles (e.g. tax, donation, or lump sum [22]), the anchoring effect (relates to the amount of starting bid) [44], the CV method used [29], the scope effect [9, 85], or the framing effect [66] can bias WTP estimates. Nevertheless, only ten studies $[9,22,26,41,62,63,66,67,75$, 79] included variables on the study design in the regression model to explain a possible influence on WTP. This result suggests that methodological variables, which could be helpful to control for bias related to the study design, are underrepresented in regression models analysing WTP. We did not expect further aspects to be addressed regarding the range of the determinants found. How the determinants are operationalised within a specific $\mathrm{CV}$ study depends on the research question and the setting. Consulting experts in the field of study will be helpful.

Instead of judging which explanatory variables are the most important determinants to use for further analyses, we aimed to create awareness for potentially significant relations between more neglected determinants and WTP. The main benefit of our research is the summary of relevant studies to show a potential lack of addressing relevant determinants in regression models. In addition, we provide studies that can be cited for theory-based variable selection or to justify the inclusion of less commonly addressed issues in $\mathrm{CV}$ questionnaires. We hope to contribute to a worthwhile and meaningful variable selection by sensitising researchers to the importance of perceived benefits and barriers related to the health services assessed, perceived susceptibility for the condition assessed, previous experiences, sociocultural, environmental, and other factors influencing the value of a health technology. For example, cultural aspects will help interpret differences in WTP between countries if social desirability, shaped by moral values of a society [30], and perceived stigma by society [86], as motivations for use, differ. The monetary value of WTP and well-chosen determinants provide important information for policymakers to understand what determines the value of a health technology for the public. Ultimately, our review may lead to better studies and better health policy decisions based on insightful information derived from a broad range of relevant determinants on what constitutes the value of a health technology to the population, regardless of the biases in the level of monetary WTP. Knowing the determinants helps to define actions, for example, information campaigns.

To our best knowledge, we are not aware of any studies directly comparable to our review. However, our results align with the limited comparable results from other published reviews. Most similar, but with a different study population and perspective, is a meta-regression by Chaikumbung [11] that evaluated WTP of chronically ill patients. Our results align with this study, showing that socioeconomic factors have a statistically significant impact on the WTP. In contrast to Chaikumbung [11], who evaluated the WTP of chronically ill patients, our review provides an overview of which factors affect WTP among citizens that are not (yet) directly affected. This does not exclude subjects indirectly affected, for example, by having risk factors or vulnerability to the illness and having learned about them or having friends or family members who have been directly affected. Another systematic review by McDougall et al. [87] pursued a different research aim but also included studies on the WTP for health. McDougall et al. [87] investigated the validity and accuracy of WTP values by comparing values from 18 studies on WTP for health or the value of a statistical life-year with national guidelines of cost-effectiveness thresholds. Consistent with our studies, they find substantial heterogeneity in the methods of eliciting WTP, resulting in a wide range of monetary values [87].

In our review, we assessed determinants of hypothetical WTP, which may or may not appropriately reflect actual WTP. A systematic review by Kanya et al. [88] using a meta-regression of 84 studies, including nine from the health care sector, has shown that the hypothetical WTP is a weak indicator of actual WTP and hypothetical WTP was 3.2-5.7 times higher than the actual WTP. The extent of the variation between actual and hypothetical WTP is likely influenced by methodological aspects, such as the different study designs [88].

However, a study performed by Quaife et al. [89] evaluated the use of discrete choice experiments in health care. Eight studies comparing hypothetical choices (predictions from the models) and real choices showed that discrete choice experiments could produce reasonable predictions if the sample represents the population [89]. According to Smith [90], the extent of the divergence between actual and 
hypothetical WTP can be accounted for since the validity of WTP increases by describing the health services assessed realistically and credibly to the respondent. The way the WTP is asked for, the time of the survey and how the respondents' risk of using the services is perceived also influence the reliability of the CV survey's results [90].

Our systematic review has several limitations. One limitation is the heterogeneity of scope and methods of the included studies. This can be traced back to the fact that they were conducted in many different countries with different cultures, infrastructural and financial resources, and different health services assessed, which makes comparison or generalisation difficult. A lack of comparability of the results with other countries is also expressed in the discussion sections of included studies (e.g. [42, 57]). In addition, the methods of data collection, analysis, and presentation vary widely across studies. WTP has been collected in different currencies and formats, as dichotomous, continuous or interval variables, with or without respondents having a WTP of zero. Hence, we have chosen not to conduct a meta-regression and provide an overview of all the determinants used in the relevant literature. Due to the lack of an appropriate assessment tool to address methodological differences, we did not assess the study quality of the included CV studies in detail but tried to limit the heterogeneity of the study objectives via our inclusion criteria.

In addition, our review itself has limitations related to the search and subjective influence of the authors. We likely missed relevant papers due to our search strings focussing on multivariate regression analyses and several exclusion criteria. However, this restriction was necessary for a feasible search and having a focussed research question. We also might not have identified some types of survival analyses or causal methods (e.g. g-methods) [91]. But since using different types of regression analyses is the most common approach for analysing CV studies, we do not expect this restriction strongly biases our set of determinants. In addition, a publication bias due to the restriction on databases cannot be excluded. However, as we included multiple health and life sciences databases in our search, this seems unlikely. Our search might have yielded more studies if we had considered languages other than English or German and searched for original publications before 1999 instead of following up on the review by Olsen and Smith 2001 [5]. We intended to identify significant determinants after adjustments for multivariate covariates. We focussed on regression analyses because this is the most common method to adjust for covariates in health economics and epidemiology.

The labels of the determinants and domains are subjective since the process of synthesising the information is based on discussions among the authors. Although this is an appropriate way to summarise the many different variables and is common practice for qualitative syntheses, the reader should not use the domains out of the context of our review. Our decision of which determinants belong to the domains "perceived threat", "perceived benefit", and "perceived barriers" is also independent of the Health Belief Model [15].

When summarising the determinants from the 62 studies, we made assumptions to simplify the synthesis and categorisation of determinants. For example, we combined several regression models presented within one publication into one assessment about the significance of the association per publication to be able to generate summary frequencies (see Table 3). We ranked these frequencies and proportions of use of the determinants (see Table 5). Still, we suggest not to interpret the 22 determinants as a suggested "core" standard set of variables or as proof for the relevance of variables. Instead, we suggest a minimum pool of potential variables to consider depending on the specific study purpose and research question. Our results should also motivate consideration of more rarely used determinants when examining the variation in WTP for health services. Explicit statements on economic theory and causal assumptions, expressed by causal diagrams [92] with theory-based variable selection instead of a solely statistically based approach, should guide the assessment of determinants and their effects. We particularly encourage including determinants describing the situation and the context of the research problem with the purpose of better understanding the complex situation of an individual when evaluating the value of health services. CV studies in health care help establish a detailed understanding of (societal) preferences and values to inform decisionmaking. Especially when trade-offs between different health services are necessary for allocation decisions to ensure against the background of economic efficiency, knowledge on societal preferences is useful.

Further research should evaluate whether using a similar set of explanatory variables in regression models analysing WTP positively affects the comparability of WTP values for different health services. Standardising the methodology of data collection and analysis could greatly facilitate the comparability of WTP results within society. As suggested by Perry-Duxbury et al. [93], the standardisation of (1) the number and order of questions and (2) the attributes and their levels could also help to assess the validity of the results of CV studies.

\section{Conclusion}

Our review provides comprehensive and quantitative evidence on 22 determinants used to analyse WTP for healthcare services from an ex-ante perspective. The thematic domains of the determinants were categorised in "sociodemographic characteristics", "perceived threat", "perceived benefit", "perceived barriers", and "other information", 
including study design and setting. Determinants describing the respondent's perception added valuable information to understand what influences the perceived value of a health service for society. Our pool of determinants can guide the planning of future WTP surveys and the analysis of data in $\mathrm{CV}$ studies in health and medicine. To consider possible relationships between variables, which may include bias and confounding but also obvious variables, for example, perceived effectiveness of the treatment or severity of the condition, at the planning stage of the study can help ensure that the relevant variables are collected and that the goodness of fit of the regression models is improved. When used to inform health policy allocation decisions, more informative models will ultimately lead to more health for the money spent. Before interpreting these determinants as causal factors and potential intervention targets, actual causal relations, endogeneity, and the choice of causal inference methods should be carefully considered.

\section{Appendix}

\section{Search strategy}

Database and search strings with number of hits for the time from January 1, 1999, to October 21, 2021.

\section{Web of Science}

Search 2020 (323 hits-24 August 2020):

$\mathrm{TS}=$ ("contingent valuation" OR "willingness to pay" OR "willingness-to-pay) AND ALL FIELDS (regression) AND $\mathrm{ALL}=$ (medical); $\mathrm{TS}=$ topic, $\mathrm{ALL}=$ all fields .

Search 2021 (374 hits-07 April 2021).

$\mathrm{TS}=$ ("contingent valuation" OR "willingness to pay" OR "willingness-to-pay") AND ALL=("regression" OR "predictor") AND ALL = (medical); TS = topic, $\mathrm{ALL}=$ all fields.

\section{Medline via Pubmed}

Search 2020 (496 hits-24 August 2020): ((contingent valuation[Title/Abstract]) OR (willingness to pay[Title/ Abstract])) AND ((regression[Title/Abstract]) OR (determinant[Title/Abstract])).

Search 2021 (1,094 hits-21 October 2021) ((“contingent valuation"[Title/Abstract] OR "willingness to pay"[Title/ Abstract])) AND (("survival function*"[Title/Abstract] OR "regression*"[Title/Abstract] OR "determinant*"[Title/ Abstract] OR "predictor*"[Title/Abstract] OR "tobit"[Title/Abstract] OR "probit"[Title/Abstract] OR "stratification"[Title/Abstract] OR "structural equation modelling"[Title/Abstract] OR "g method*"[Title/Abstract] OR "propensity score"[Title/Abstract]) OR (("propensity score" [MeSH Terms] OR "latent class analysis" [MeSH Terms] OR "social class/statistics and numerical data"
[MeSH Terms] OR "Mediation Analysis"[MeSH Terms]) OR (analyses, regression[MeSH Terms]))).

3. EconLit, ERIC, SocINDEX (via EBSCO host) (591 hits) Search 2020 (591 hits-24 August 2020):

TI ((contingent valuation OR "willingness to pay" OR "willingness-to-pay")) OR AB ((contingent valuation OR "willingness to pay" OR "willingness-to-pay")) AND TI (regression OR determinant OR predictor) OR AB (regression OR determinant OR predictor); Expanders: Apply equivalent subjects.

\section{Psycinfo, PsycarticleS (via EBSCO host) (215} hits).

Search 2020 (215 hits-24 August 2020): (TI (contingent valuation OR "willingness to pay" OR "willingness-to-pay) OR AB (contingent valuation OR "willingness to pay" OR "willingness-to-pay)) AND (TI (regression OR determinant) OR AB (regression OR determinant)); Expanders: Apply equivalent subjects.

\section{BIOSIS Previews, Embase, Ovid MEDLINE(R) and Epub Ahead of Print (via Ovid)}

Search 2020 (1,020 hits-24 August 2020): ((contingent valuation or willingness to pay or willingness-to-pay).ti.) OR ((contingent valuation or willingness to pay or willingness-to-pay).ab.) AND ((regression or determinant).ab. OR (regression or determinant).ti.)

Search 2021 (1,325 hits—07 April 2021): ((contingent valuation or willingness to pay or willingness-to-pay).ti. or (contingent valuation or willingness to pay or willingnessto-pay).ab.) and ((regression or predictor or determinant). ti.). or (regression or predictor or determinant).ab.)

Supplementary Information The online version contains supplementary material available at https://doi.org/10.1007/s10198-022-01437-x.

Author contributions All the authors contributed to the study conception and design. Material preparation, data collection and analysis were performed by Magdalena Flatscher-Thoeni and Caroline Steigenberger. The first draft of the manuscript was written by Caroline Steigenberger, and all the authors commented on previous versions of the manuscript. All the authors read and approved the final manuscript.

Funding The authors have no relevant financial or non-financial interests to disclose.

\section{Declarations}

Conflict of interest The authors have no conflicts of interest to declare that are relevant to the content of this article. All the authors certify that they have no affiliations with or involvement in any organisation or entity with any financial interest or non-financial interest in the subject matter or materials discussed in this manuscript. The authors have 
no financial or proprietary interests in any material discussed in this article.

\section{References}

1. Klose, T.: The contingent valuation method in health care. Health Policy 47(2), 97-123 (1999)

2. Drummond, M., Sculpher, M., Torrance, G., O’Brien, B., Stoddart, G.: Chapter 7: cost-benefit analysis. In: Methods for the economic evaluation of health care programmes, 3rd edn., pp. 211-245. Oxford University Press, New York (2005)

3. Carson, R.T.: Contingent valuation: a practical alternative when prices aren't available. J. Econ. Perspect. 26(4), 27-42 (2012)

4. Cambridge University Press: Definition of health service Cambridge University Press. https://dictionary.cambridge.org/de/worte rbuch/englisch/health-service (2020). Accessed 10 Nov 2020

5. Olsen, J.A., Smith, R.D.: Theory versus practice: a review of 'willingness-to-pay' in health and health care. Health Econ. 10(1), 39-52 (2001)

6. Mitchell, R.C., Carson, R.T.: Using surveys to value public goods: the contingent valuation method. RFF Press (1989)

7. Diener, A., O'Brien, B., Gafni, A.: Health care contingent valuation studies: a review and classification of the literature. Health Econ. 7(4), 313-326 (1998)

8. Venkatachalam, L.: The contingent valuation method: a review. Environ. Impact Assess. Rev. 24, 89-124 (2004)

9. Poder, T.G., He, J., Simard, C., Pasquier, J.C.: Willingness to pay for ovulation induction treatment in case of WHO II anovulation: a study using the contingent valuation method. Patient Preference Adherence 8, 1337-1346 (2014)

10. Jansen, S.J., Stiggelbout, A.M., Wakker, P.P., Nooij, M.A., Noordijk, E.M., Kievit, J.: Unstable preferences: a shift in valuation or an effect of the elicitation procedure? Med. Decis. Mak. 20(1), 62-71 (2000)

11. Chaikumbung, M.: Institutions, culture, and chronically ill patients' willingness to pay for medical treatment: a meta-regression analysis. J. Public Health (Germany) (2020)

12. Rotteveel, A.H., Lambooij, M.S., Zuithoff, N.P.A., van Exel, J., Moons, K.G.M., de Wit, G.A.: Valuing healthcare goods and services: a systematic review and meta-analysis on the WTA-WTP disparity. Pharmacoeconomics 38(5), 443-458 (2020)

13. Kouakou, C.R.C., Poder, T.G.: Willingness to pay for a quality-adjusted life year: a systematic review with meta-regression. Eur. J. Health Econ. (2021). https://doi.org/10.1007/ s10198-021-01364-3

14. Ye, Z., Ma, J., Liu, F., Wang, C., Zhou, Z., Sun, L.: A systematic review and meta-regression of studies eliciting willingness-to-pay per quality-adjusted life year in the general population. Expert Rev. Pharmacoecon. Outcomes Res. (2021)

15. Rosenstock, I.M.: Why people use health services. Milbank Mem. Fund Q. 44(3), 94-127 (1966)

16. Naing, C.M., Lertmaharit, S., Kamol-Ratanakul, P., Saul, A.J.: Ex post and ex ante willingness to pay (WTP) for the ICT malaria $\mathrm{Pf} / \mathrm{Pv}$ test kit in Myanmar. Southeast Asian. J. Trop. Med. 31(1), 104-111 (2000)

17. Rachlin, H., Jones, B.A.: Altruism among relatives and non-relatives. Behav. Process. 79(2), 120-123 (2008)

18. Yen, Z.S., Chang, C.J., Chen, S.Y., Lee, C.C., Hsu, C.Y., Chen, S.C., et al.: How much would you be willing to pay for preventing a new dangerous infectious disease: a willingness-to-pay study in medical personnel working in the emergency department. Am. J. Infect. Control 35(8), 516-520 (2007)
19. Hanley, N., Ryan, M., Wright, R.: Estimating the monetary value of health care: lessons from environmental economics. Health Econ. 12(1), 3-16 (2003)

20. Arrow, K., Solow, R., Portney, P.R., Leamer, E.E., Radner, R., Schuman, H.: Report of the NOAA panel on contingent valuation. Fed. Reg. 58(10), 4601-4614 (1993)

21. O'Brien, B., Gafni, A.: When do the "dollars" make sense? Toward a conceptual framework for contingent valuation studies in health care. Med. Decis. Mak. 16(3), 288-299 (1996)

22. Poder, T.G., He, J.: Willingness to pay and the sensitivity of willingness to pay for interdisciplinary musculoskeletal clinics: a contingent valuation study in Quebec, Canada. Int. J. Health Econ. Manag. 16(4), 337-361 (2016)

23. Al-Hanawi, M.K., Alsharqi, O., Vaidya, K.: Willingness to pay for improved public health care services in Saudi Arabia: a contingent valuation study among heads of Saudi households. Health Econ. Policy Law 15(1), 72-93 (2020)

24. Arize, I., Onwujekwe, O.: Acceptability and willingness to pay for telemedicine services in Enugu state, southeast Nigeria. Digit. Health (2017). https://doi.org/10.1177/2055207617715524

25. Basu, R.: Willingness-to-pay to prevent Alzheimer's disease: a contingent valuation approach. Int. J. Health Care Finance Econ. 13(3-4), 233-245 (2013)

26. Carlsson, K.S., Höjgård, S., Lethagen, S., Lindgren, A., Berntorp, E., Lindgren, B.: Willingness to pay for on-demand and prophylactic treatment for severe haemophilia in Sweden. Haemophilia 10(5), 527-541 (2004)

27. Catma, S., Varol, S.: Willingness to pay for a hypothetical COVID-19 vaccine in the United States: a contingent valuation approach. Vaccines (Basel) (2021). https://doi.org/10.3390/vacci nes9040318

28. Cerda, A.A., García, L.Y.: Willingness to pay for a COVID-19 vaccine. Appl. Health Econ. Health Policy 19(3), 343-351 (2021)

29. Dieng, A., He, J., Poder, T.G.: Web comparison of three contingent valuation techniques in women of childbearing age: the case of ovulation induction in Quebec. Interact. J. Med. Res. 9(1), e13355 (2020)

30. Gonen, L.D.: And when i die: theory of planned behavior as applied to sperm cryopreservation. Healthcare (Basel) (2021). https://doi.org/10.3390/healthcare9050554

31. Hansen, K.S., Pedrazzoli, D., Mbonye, A., Clarke, S., Cundill, B., Magnussen, P., et al.: Willingness-to-pay for a rapid malaria diagnostic test and artemisinin-based combination therapy from private drug shops in Mukono district, Uganda. Health Policy Plan. 28(2), 185-196 (2013)

32. Harapan, H., Wagner, A.L., Yufika, A., Winardi, W., Anwar, S., Gan, A.K., et al.: Willingness-to-pay for a COVID-19 vaccine and its associated determinants in Indonesia. Hum. Vaccines Immunother. 16(12), 3074-3080 (2020)

33. Himmler, S., van Exel, J., Perry-Duxbury, M., Brouwer, W.: Willingness to pay for an early warning system for infectious diseases. Eur. J. Health Econ. 21(5), 763-773 (2020)

34. Kim, A.R., Lee, S.M., An, S.: Estimating the economic value of counselling services using the contingent valuation method. Psychother. Res. 28(5), 820-828 (2018)

35. Kim, M.O., Lee, K.S., Kim, J.H., Joo, J.S.: Willingness to pay for hospice care using the contingent valuation method. Yonsei Med. J. 52(3), 510-521 (2011)

36. Mavrodi, A.G., Chatzopoulos, S.A., Aletras, V.H.: Examining willingness-to-pay and zero valuations for a health improvement with logistic regression. Inquiry 58, 469580211028102 (2021)

37. Milligan, M.A., Bohara, A.K., Pagán, J.A.: Assessing willingness to pay for cancer prevention. Int. J. Health Care Finance Econ. 10(4), 301-314 (2010) 
38. Onwujekwe, O., Ogbonna, C., Ibe, O., Uzochukwu, B.: Willingness to pay and benefit-cost analysis of modern contraceptives in Nigeria. Int. J. Gynecol. Obstet. 122(2), 94-98 (2013)

39. Oremus, M., Tarride, J.E., Clayton, N., Raina, P.: Support for a tax increase to provide unrestricted access to an Alzheimer's disease medication: a survey of the general public in Canada. BMC Health Serv. Res. 9, 246 (2009)

40. Rheingans, R.D., Haddix, A.C., Messonnier, M.L., Meltzer, M., Mayard, G., Addiss, D.G.: Willingness to pay for prevention and treatment of lymphatic filariasis in Leogane. Haiti. Filaria J. 3, 2 (2004)

41. Saengow, U., Birch, S., Geater, A., Chongsuwiwatvong, V.: Willingness to pay for colorectal cancer screening and effect of copayment in Southern Thailand. Asian Pac. J. Cancer Prev. 19(6), 1727-1734 (2018)

42. Sarasty, O., Carpio, C.E., Hudson, D., Guerrero-Ochoa, P.A., Borja, I.: The demand for a COVID-19 vaccine in Ecuador. Vaccine 38(51), 8090-8098 (2020)

43. Sarker, A.R., Islam, Z., Sultana, M., Sheikh, N., Mahumud, R.A., Islam, M.T., et al.: Willingness to pay for oral cholera vaccines in urban Bangladesh. PLoS One (2020). https://doi.org/10.1371/ journal.pone. 0232600

44. Ternent, L., McNamee, P., Newlands, D., Belemsaga, D., Gbangou, A., Cross, S.: Willingness to pay for maternal health outcomes: are women willing to pay more than men? Appl. Health Econ. Health Policy 8(2), 99-109 (2010)

45. Tran, B.X., Than, P.T.Q., Doan, T.T.N., Nguyen, H.L.T., Mai, H.T., Nguyen, T.H.T., et al.: Knowledge, attitude, and practice on and willingness to pay for human papillomavirus vaccine: a crosssectional study in Hanoi, Vietnam. Patient Preference Adherence 12, 945-954 (2018)

46. Wang, Q., Zhou, Y., Ding, X.R., Ying, X.H.: Demand for longterm care insurance in China. Int. J. Environ. Res. Public Health 15(1), 6 (2018)

47. Yasunaga, H.: Willingness to pay for mass screening for prostate cancer: a contingent valuation survey. Int. J. Urol. 15(1), 102-105 (2008). (Discussion 105)

48. Yasunaga, H.: Who wants cancer screening with PET? A contingent valuation survey in Japan. Eur. J. Radiol. 70(1), 190-194 (2009)

49. Yasunaga, H., Ide, H., Imamura, T., Ohe, K.: Women's anxieties caused by false positives in mammography screening: a contingent valuation survey. Breast Cancer Res. Treat. 101(1), 59-64 (2007)

50. Yasunaga, H., Sugihara, T., Imamura, T.: Difference in willingness-to-pay for prostate cancer screening between ill-informed and well-informed men: a contingent valuation survey. Urology 77(6), 1325-1329 (2011)

51. Bishai, D., Pariyo, G., Ainsworth, M., Hill, K.: Determinants of personal demand for an AIDS vaccine in Uganda: contingent valuation survey. Bull. World Health Organ. 82(9), 652-660 (2004)

52. Habbani, K., Groot, W., Jelovac, I.: Household health-seeking behaviour in Khartoum, Sudan: the willingness to pay for public health services if these services are of good quality. Health Policy 75(2), 140-158 (2006)

53. Kitajima, T.: Willingness to pay for long-term care insurance system in a municipality in Tokyo. Asia Pac. J. Public Health 11(2), 101-108 (1999)

54. Lakic, D., Stevic, I., Odalovic, M., Vezmar-Kovacevic, S., Tadic, I.: Patients' willingness to pay for cognitive pharmacist services in community pharmacies. Croat. Med. J. 58(5), 364-371 (2017)

55. Nayak, S., Roberts, M.S., Greenspan, S.L.: Osteoporosis screening preferences of older adults. J. Clin. Densitom. 12(3), 279-286 (2009)

56. Onwujekwe, O.E., Ogbonna, C., Uguru, N., Uzochukwu, B.S.C., Lawson, A., Ndyanabangi, B.: Increasing access to modern contraceptives: the potential role of community solidarity through altruistic contributions. Int. J. Equity Health (2012). https://doi. org/10.1186/1475-9276-11-34

57. Rajamoorthy, Y., Radam, A., Taib, N.M., Ab Rahim, K., Munusamy, S., Wagner, A.L., et al.: Willingness to pay for hepatitis B vaccination in Selangor, Malaysia: a cross-sectional household survey. PLoS One (2019). https://doi.org/10.1371/journal. pone. 0215125

58. Trudeau, J.M., Alicea-Planas, J., Vásquez, W.F.: The value of COVID-19 tests in Latin America. Econ. Hum. Biol. 39, 100931 (2020)

59. Yang, F., Gannon, B., Weightman, A.: Public's willingness to pay towards a medical device for detecting foot ulceration in people with diabetes. Appl. Health Econ. Health Policy 16(4), 559-567 (2018)

60. Baji, P., Pavlova, M., Gulácsi, L., Farkas, M., Groot, W.: The link between past informal payments and willingness of the Hungarian population to pay formal fees for health care services: results from a contingent valuation study. Eur. J. Health Econ. 15(8), 853-867 (2014)

61. Bouvy, J., Weemers, J., Schellekens, H., Koopmanschap, M.: Willingness to pay for adverse drug event regulatory actions. Pharmacoeconomics 29(11), 963-975 (2011)

62. Frew, E., Wolstenholme, J.L., Whynes, D.K.: Willingness-to-pay for colorectal cancer screening. Eur. J. Cancer 37(14), 1746-1751 (2001)

63. Lamiraud, K., von Bremen, K., Donaldson, C.: The impact of information on patient preferences in different delivery patterns: a contingent valuation study of prescription versus OTC drugs. Health Policy 93(2-3), 102-110 (2009)

64. Pavlova, M., Groot, W., van Merode, G.: Willingness and ability of Bulgarian consumers to pay for improved public health care services. Appl. Econ. 36(10), 1117-1130 (2004)

65. Udezi, W.A., Usifoh, C.O., Ihimekpen, O.O.: Willingness to pay for three hypothetical malaria vaccines in Nigeria. Clin. Ther. 32(8), 1533-1544 (2010)

66. Whynes, D.K., Frew, E., Wolstenholme, J.L.: A comparison of two methods for eliciting contingent valuations of colorectal cancer screening. J. Health Econ. 22(4), 555-574 (2003)

67. Wolff, E., Larsson, S., Svensson, M.: Willingness to pay for health improvements using stated preferences: prevention versus treatment. Value Health 23(10), 1384-1390 (2020)

68. Wong, L.P., Alias, H., Wong, P.F., Lee, H.Y., AbuBakar, S.: The use of the health belief model to assess predictors of intent to receive the COVID-19 vaccine and willingness to pay. Hum. Vaccines Immunother. 16(9), 2204-2214 (2020)

69. Yasunaga, H., Ide, H., Imamura, T., Ohe, K.: Analysis of factors affecting willingness to pay for cardiovascular disease-related medical services. Int. Heart J. 47(2), 273-286 (2006)

70. Yasunaga, H., Ide, H., Imamura, T., Ohe, K.: The measurement of willingness to pay for mass cancer screening with whole-body PET (positron emission tomography). Ann. Nucl. Med. 20(7), 457-462 (2006)

71. Yasunaga, H., Ide, H., Imamura, T., Ohe, K.: Benefit evaluation of mass screening for prostate cancer: willingness-to-pay measurement using contingent valuation. Urology 68(5), 1046-1050 (2006)

72. Borges, A.P., Reis, A., Anjos, J.: Willingness to pay for other individuals' healthcare expenditures. Public Health 144, 64-69 (2017)

73. Brau, R., Lippi Bruni, M., Pinna, A.M.: Public versus private demand for covering long-term care expenditures. Appl. Econ. 42(28-30), 3651-3668 (2010)

74. Kim, C.O., Jang, S.N.: Who are the people willing to pay for physician home visits? J. Korean Med. Sci. (2020). https://doi. org/10.3346/jkms.2020.35.e158 
75. Pavel, M.S., Chakrabarty, S., Gow, J.: Assessing willingness to pay for health care quality improvements. BMC Health Serv. Res. (2015). https://doi.org/10.1186/s12913-015-0678-6

76. Rezaei, S., Woldemichael, A., Mirzaei, M., Mohammadi, S., Matin, B.K.: Mothers' willingness to accept and pay for vaccines to their children in western Iran: a contingent valuation study. BMC Pediatrics (2020). https://doi.org/10.1186/ s12887-020-02208-4

77. Schulz, R., Beach, S.R., Matthews, J.T., Courtney, K., Devito Dabbs, A., Person Mecca, L., et al.: Willingness to pay for quality of life technologies to enhance independent functioning among baby boomers and the elderly adults. Gerontologist 54(3), 363374 (2014)

78. Seyedin, H., Safari, M., Parnian, E.: Willingness-to-pay for improvement of hypothetical health status in patients visiting the emergency department: a contingent valuation study. Clin. Epidemiol. Glob. Health 8(1), 66-69 (2020)

79. Terashita, T., Muto, H., Nakamura, T., Ogasawara, K., Maezawa, M.: Willingness to pay for municipality hospital services in rural Japan: a contingent valuation study. BMC Res. Notes 4, 177 (2011)

80. Wang, J., Lyu, Y., Zhang, H., Jing, R., Lai, X., Feng, H., et al.: Willingness to pay and financing preferences for COVID-19 vaccination in China. Vaccine 39(14), 1968-1976 (2021)

81. Whittington, D., Matsui-Santana, O., Freiberger, J.J., Van Houtven, G., Pattanayak, S.: Private demand for a HIV/AIDS vaccine: evidence from Guadalajara, Mexico. Vaccine 20(19-20), 2585-2591 (2002)

82. Banik, R., Islam, M.S., Pranta, M.U.R., Rahman, Q.M., Rahman, M., Pardhan, S., et al.: Understanding the determinants of COVID-19 vaccination intention and willingness to pay: findings from a population-based survey in Bangladesh. BMC Infect. Dis. 21(1), 892 (2021)

83. World Bank Group: Regional Perspectives. https://www.world bank.org/en/about/annual-report/region-perspectives (2021). Accessed 08 Nov 2021

84. Lederer, D.J., Bell, S.C., Branson, R.D., Chalmers, J.D., Marshall, R., Maslove, D.M., et al.: Control of confounding and reporting of results in causal inference studies. Guidance for authors from editors of respiratory, sleep, and critical care journals. Ann. Am. Thorac. Soc. 16(1), 22-28 (2019)

85. Borzykowski, N., Baranzini, A., Maradan, D.: Scope effects in contingent valuation: does the assumed statistical distribution of WTP matter? Ecol. Econ. 144, 319-329 (2018)

86. Audureau, E., Davis, B., Besson, M.H., Saba, J., Ladner, J.: Willingness to pay for medical treatments in chronic diseases: a multicountry survey of patients and physicians. J. Comp. Eff. Res. 8(5), 357-369 (2019)

87. McDougall, J.A., Furnback, W.E., Wang, B.C.M., Mahlich, J.: Understanding the global measurement of willingness to pay in health. J. Mark. Access Health Policy 8(1), 1717030 (2020)

88. Kanya, L., Sanghera, S., Lewin, A., Fox-Rushby, J.: The criterion validity of willingness to pay methods: a systematic review and meta-analysis of the evidence. Soc. Sci. Med. 232, 238-261 (2019)

89. Quaife, M., Terris-Prestholt, F., Di Tanna, G.L., Vickerman, P.: How well do discrete choice experiments predict health choices? A systematic review and meta-analysis of external validity. Eur. J. Health Econ. 19(8), 1053-1066 (2018)

90. Smith, R.D.: Construction of the contingent valuation market in health care: a critical assessment. Health Econ. 12(8), 609-628 (2003)

91. Robins, J.M., Hernán, M.A., Siebert, U.: Estimations of the effects of multiple interventions. In: Ezzati, M., Lopez, A.D., Rodgers, A., Murray, C.J.L. (eds.) Comparative quantification of health risks: global and regional burden of disease attributable to selected major risk factors, pp. 2191-2230. World Health Organization, Geneva (2004)

92. Greenland, S., Pearl, J., Robins, J.M.: Causal diagrams for epidemiologic research. Epidemiology 10(1), 37-48 (1999)

93. Perry-Duxbury, M., van Exel, J., Brouwer, W.: How to value safety in economic evaluations in health care? A review of applications in different sectors. Eur. J. Health Econ. 20(7), 1041-1061 (2019)

Publisher's Note Springer Nature remains neutral with regard to jurisdictional claims in published maps and institutional affiliations. 